Article

\title{
Fragment-Based Lead Generation of 5-Phenyl-1H-pyrazole-3-carboxamide Derivatives as Leads for Potent Factor Xia Inhibitors
}

\author{
Qunchao Wei ${ }^{1,2}{ }^{\text {, Zhichao Zheng }}{ }^{2}$, Shijun Zhang ${ }^{2}$, Xuemin Zheng ${ }^{2}$, Fancui Meng ${ }^{2}$ (D), \\ Jing Yuan ${ }^{2}$, Yongnan $\mathrm{Xu}^{1, *}$ and Changjiang Huang ${ }^{2, *}$ \\ 1 School of Pharmaceutical Engineering, Shenyang Pharmaceutical University, Shenyang 110016, China; \\ wei_qunchao@126.com \\ 2 Tianjin Key Laboratory of Molecular Design and Drug Discovery, Tianjin Institute of Pharmaceutical \\ Research, Tianjin 300193, China; zhengzc@tjipr.com (Z.Z.); zhangsj@tjipr.com (S.Z.); \\ zhengxm@tjipr.com (X.Z.); mengfc@tjipr.com (F.M.); yuanj@tjipr.com (J.Y.) \\ * Correspondence: ynxu@syphu.edu.cn or ynanxu@hotmail.com (Y.X.); huangcj@tjipr.com (C.H.); \\ Tel.: +86-24-4352-0248 (Y.X.); +86-22-2300-6833 (C.H.)
}

Academic Editor: Johannes Reynisson

Received: 23 July 2018; Accepted: 9 August 2018; Published: 10 August 2018

\begin{abstract}
FXIa is suggested as a major target for anticoagulant drug discovery because of reduced risk of bleeding. In this paper, we defined 5-phenyl-1H-pyrazole-3-carboxylic acid derivatives as privileged fragments for FXIa inhibitors' lead discovery. After replacing the (E)-3-(5-chloro-2(1H-tetrazol-1-yl)phenyl)acrylamide moiety in compound 3 with 5-(3-chlorophenyl)-1H-pyrazole-3carboxamide, we traveled from FXIa inhibitor 3 to a scaffold that fused the privileged fragments into a pharmacophore for FXIa inhibitors. Subsequently, we synthesized and assessed the FXIa inhibitory potency of a series of 5-phenyl-1H-pyrazole-3-carboxamide derivatives with different P1, P1' and P2'moiety. Finally, the SAR of them was systematically investigated to afford the lead compound 7za $($ FXIa Ki $=90.37 \mathrm{nM}, 1.5 \times$ aPTT in rabbit plasma $=43.33 \mu \mathrm{M}$ ) which exhibited good in vitro inhibitory potency against FXIa and excellent in vitro coagulation activities. Furthermore, the binding mode of 7za with FXIa was studied and the results suggest that the 2-methylcyclopropanecarboxamide group of 7za makes 2 direct hydrogen bonds with Tyr58B and Thr35 in the FXIa backbone, making 7za binds to FXIa in a highly efficient manner.
\end{abstract}

Keywords: thrombosis; coagulation factors; FXIa inhibitors; docking stimulation; computer-aided drug design

\section{Introduction}

Cardiovascular (CV) disease continues to be the leading cause of death worldwide [1]. Thrombosis is the common underlying pathology of cardiovascular diseases and anticoagulants are the mainstay to prevent and/or treat thrombosis [2]. In clinical use, anticoagulants include antithrombin activators (heparins including unfractionated heparin, low molecular weight heparins and fondaparinux), vitamin $\mathrm{K}$ antagonists (coumarins such as warfarin), direct inhibitors of thrombin (hirudins, argatroban and dabigatran etexilate) and oral direct FXa inhibitors (rivaroxaban, apixaban, edoxaban and betrixaban) [3]. Although these agents possess high efficacy and relatively low cost to benefit ratio, they stillremain be associated with the life-threatening side effect of internal bleeding [4,5]. Therefore, despite the progresses made in past few years, there is also an urgent clinical need for developing new anticoagulants to prevent and/or treat thromboembolic diseases without the risk of bleeding or with low bleeding risk. 
Generally, it is known from coagulation cascade that proteins in the intrinsic pathway are more important for the amplification phase of coagulation, whereas those belonging to the extrinsic and common coagulation pathways are more involved in the initiation and propagation phases. Current anticoagulants used for treating thrombosis mainly target two key serine proteases, thrombin and factor $\mathrm{Xa}(\mathrm{FXa})$, and they both belong to the common pathway of the coagulation cascade. Meanwhile, it has been postulated that selective inhibition of intrinsic coagulation factors could provide antithrombotic benefits with low bleeding risk because this will keep the other pathways of coagulation intact for hemostasis [6-8]. It's shown by epidemiological and clinical studies that the inhibition of Factor XIa (FXIa) which belongs to the intrinsic pathway of the coagulation cascade has emerged as an excellent way to achieve anticoagulation without significant effects on hemostasis [9]. Human FXI deficiency (hemophilia C) was first described as a mild to moderate bleeding disorder [10]. However, these affected patients rarely suffer from spontaneous bleeding episodes. Furthermore, epidemiologic studies showed an increased risk of thrombosis in subjects with elevated FXI levels and some protection from thrombosis in subjects with reduced FXI levels [11,12]. Furthermore, the open-label, parallel-group Phase II study (NCT01713361) showed that reducing FXI levels specifically by an antisense oligonucleotide in patients undergoing elective knee arthroplasty was an effective method for postoperative venous thromboembolism prevention and appeared to be safe with respect to the risk of bleeding [13]. In addition, the Phase I study (NCT03197779) showed that the small molecule FXIa inhibitor BMS-962212 had good enough tolerability, pharmacokinetics and pharmacodynamics properties suitable for investigational use as an acute antithrombotic agent in Japanese or non-Japanese subjects $[14,15]$. In summary, FXIa is suggested as a major target for anticoagulant drug discovery because of reduced risk of bleeding [7].

In recent years, lots of small molecule FXIa inhibitors were reported, including compounds 1-6 [16-21] and BMS-962212 [15] (Figure 1). Nevertheless, small molecule FXIa inhibitors' research remained in clinical phase. Further development of novel small molecule FXIa inhibitors and investigation of their Structure-Activity Relationships (SAR) are required. It was reported compound 3 exhibited good FXIa affinity activities (FXIa $\mathrm{Ki}=2 \mathrm{nM}$ ) but short $\mathrm{t}_{1 / 2}$ lives and other drawbacks.

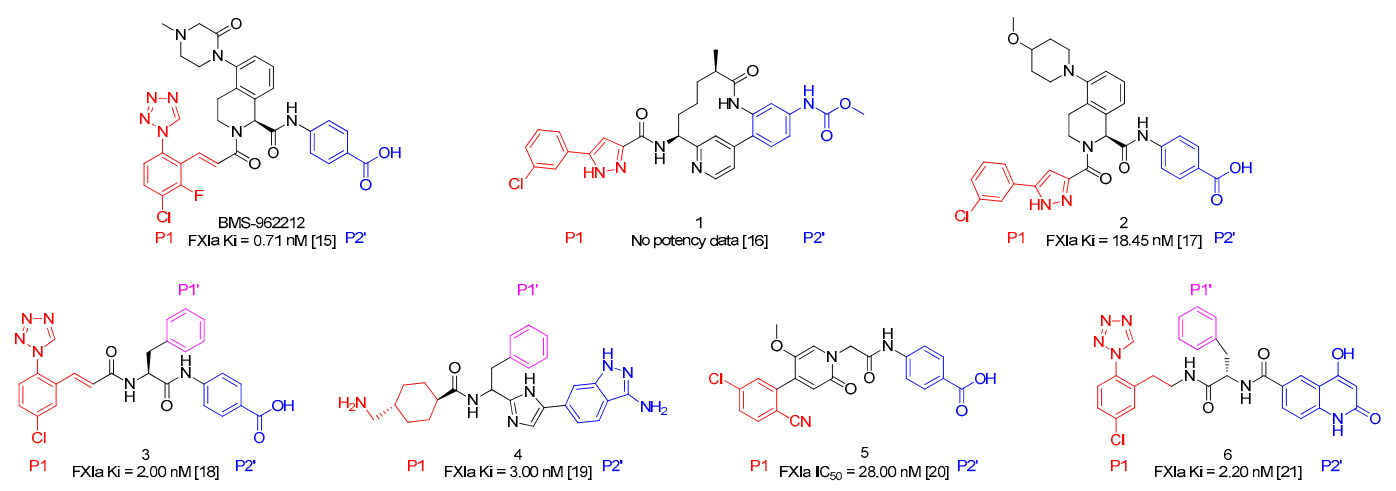

Figure 1. The representative FXIa inhibitors.

As shown in Figure 2a, the structure 3 binds to FXIa in S1-S1'-S2' mode. P1, P1 prime (P1') and P2 prime ( $\left.\mathrm{P} 2^{\prime}\right)$ moieties of compound 3 occupy the $\mathrm{S} 1$, $\mathrm{S}^{\prime}$ and $\mathrm{S} 2^{\prime}$ pocket of FXIa (Figure 2a). The carbonyl groups of the cinnamide linker in the $\mathrm{P} 1$ and $\mathrm{P} 1^{\prime}$ moieties are well positioned within the oxyanion hole by forming key hydrogen bonds with Ser195 residue (Figure 2b); In addition, the amide NH functional group forms a water mediated hydrogen bond with Leu41 [18]. It's obvious that the mentioned two linkers are crucial to ligands' binding mode and it's necessary to retain the two linkers in the structure optimization. 


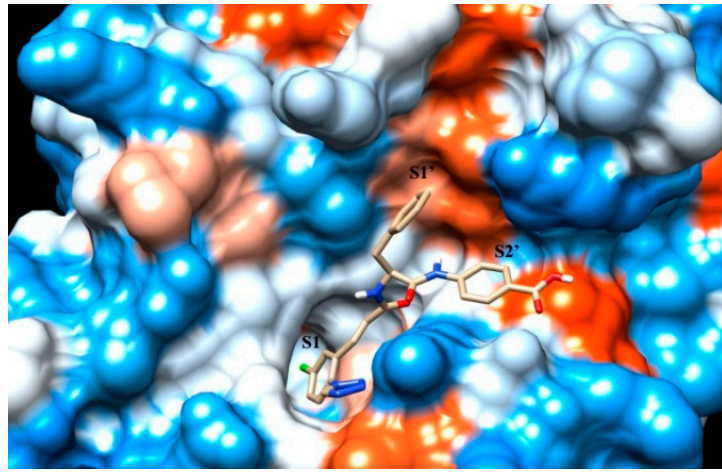

(a)

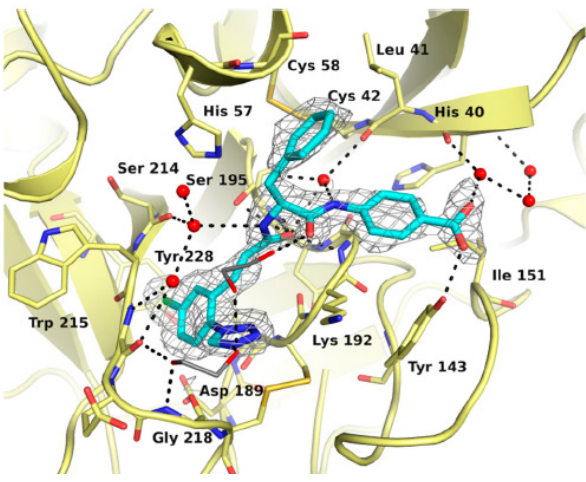

(b)

Figure 2. (a) Crystal structure of compound 3 in complex with FXIa (Hydrophobicity surface, PDB ID 5E2O); (b) Crystal structure of compound 3 in complex with FXIa (Binding mode) [18].

It's summarized that some known FXIa inhibitors such as compound 3, 4, 6 (Figure 1) were consisted of 4 parts- $\mathrm{P} 1$, P1 prime ( $\left.\mathrm{P} 1^{\prime}\right)$, P2 prime ( $\left.\mathrm{P} 2^{\prime}\right)$ moieties and scaffold. It's the molecule which was developed as a FXIa inhibitor and each part of the molecule was necessary but might be not crucial for the overall activity generally. Therefore, it's reasonable to choose an useful building block as part of FXIa inhibitors. Meanwhile, it is shown clearly that compounds 1-2 and 8-10 (Figure 3) were all based on the 5-phenyl-1H-pyrazole-3-carboxylic acid building block. Of them, compound 8 was a tissue-nonspecific alkaline phosphatase (TNAP) inhibitor [22], compound 9 was an enkephalinase inhibitor [23], compound $\mathbf{1 0}$ was a mGlu5 receptor negative allosteric modulator and compounds $\mathbf{1}$ and 2 both were FXIa inhibitors $[16,17,24]$. Thus, novel FXIa inhibitors might be developed based on the excellent 5-phenyl-1H-pyrazole-3-carboxylic acid derivatives by using the Fragment Based Lead Generation strategy.
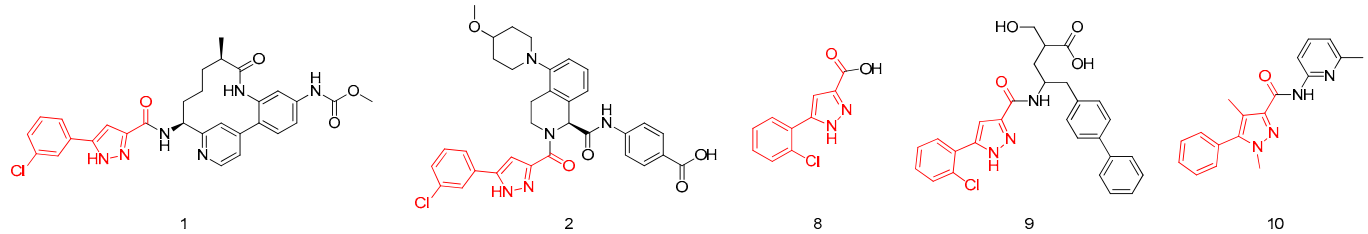

Figure 3. Representative pyrazole derivatives.

Furthermore, it was known that structure optimization using an optimal neutral P1 moiety could significantly facilitate identification of a potent, orally bioavailable FXIa inhibitor [25]. Taking these points into account, we replaced the P1 moiety in compound 3 with more neutral chloro-benzene leading to compound $7 \mathbf{a}$ and further modification of $\mathrm{P} 1, \mathrm{P} 1^{\prime}$ and $\mathrm{P} 2^{\prime}$ moieties in $7 \mathbf{a}$ furnished a series of 5-phenyl-1H-pyrazole-3-carboxamide FXIa inhibitors, of which the SAR was then systematically investigated (Figure 4).<smiles>O=C(/C=C/c1cccc(-c2ccccc2)c1)NC(Cc1ccccc1)C(=O)Nc1ccc(C(=O)O)cc1</smiles>

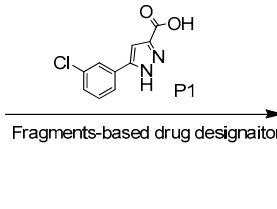

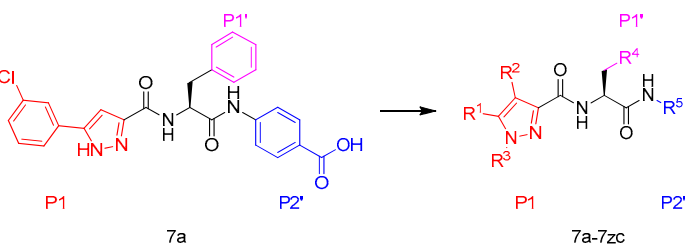

Figure 4. Design of FXIa inhibitors in present study. 
in DMF.Removal of $N$-Boc in 19a with hydrochloric ethyl acetate and the subsequent reaction with $11 f$ in the presence of1-hydroxybenzotriazole, $N$-(3-dimethyl-aminopropyl)- $N$ '-ethylcarbodiimide hydrochloride and $N, N$-diisopropylethylamine in DMF yielded 20a. Hydrolysis of 20a with $\mathrm{LiOH} \cdot \mathrm{H}_{2} \mathrm{O}$ in aqueous ethanol and acidification with $1 \mathrm{M}$ hydrochloric acid afforded $7 \mathbf{t}$. Compounds $20 \mathbf{b}$ and $7 \mathbf{u}$ were prepared according to the procedure described for the preparation of $20 \mathbf{a}$ and $7 \mathbf{t}$.

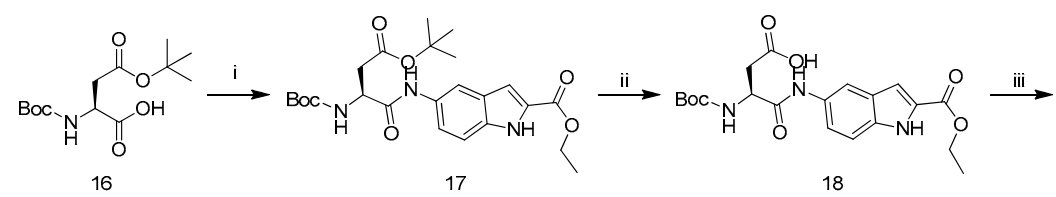

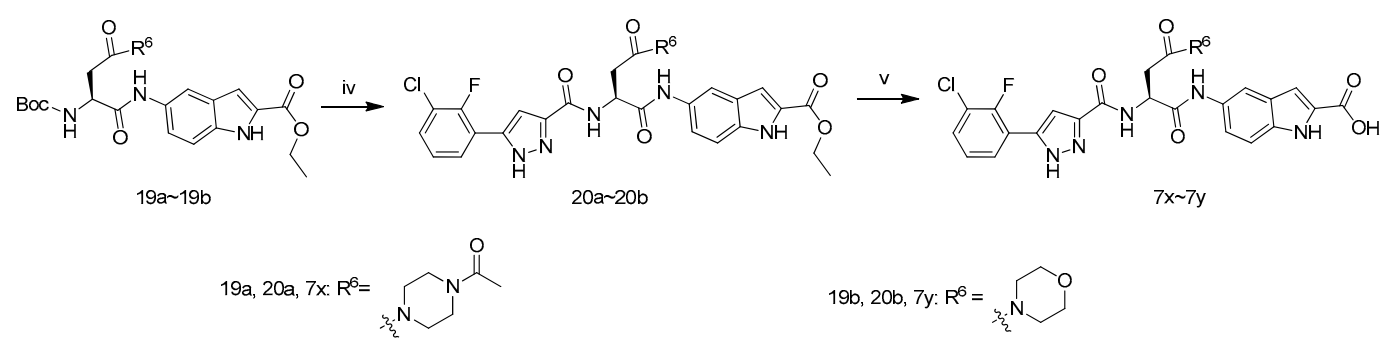

Scheme 3. Synthetic route of compounds $7 \mathbf{x}-7 \mathbf{y}$. Reagents and conditions: (i) $\mathrm{POCl}_{3}$, Pyridine, ethyl 5-amino-1H-indole-2-carboxylate, $0{ }^{\circ} \mathrm{C}$; (ii) (1) TFA: $\mathrm{CH}_{2} \mathrm{Cl}_{2}=1: 1$; (2) (Boc) ${ }_{2} \mathrm{O}, \mathrm{Et}_{3} \mathrm{~N}, \mathrm{CH}_{2} \mathrm{Cl}_{2}$; (iii) for 19a: 1-(piperazin-1-yl)ethanone, HOBT, EDCI, DIEA, DMF, r.t.; for 19b: morpholine, HOBT, EDCI, DIEA, DMF, r.t.; (iv) (1) $\mathrm{HCl} /$ EtOAc, r.t.; (2) 11f, HOBT, EDCI, DIEA, DMF, r.t.; (v) (1) $\mathrm{LiOH}^{\circ} \mathrm{H}_{2} \mathrm{O}$, $\mathrm{EtOH}, \mathrm{H}_{2} \mathrm{O}$, r.t.; (2) $1 \mathrm{M}$ hydrochloric acid.

The synthetic route to target compounds $\mathbf{7 z}, \mathbf{7 z a}-\mathbf{7 z c}$ is illustrated in Scheme 4. Coupling of carboxylic acid 11f with amine $\mathbf{2 1}$ in the presence of 1-hydroxybenzotriazole, $N$-(3-dimethyl-aminopropyl)- $N$-ethylcarbodiimide hydrochloride and $N, N$-diisopropylethylamine in DMF at room temperature, followed by the hydrolysiswithLiOH $\cdot \mathrm{H}_{2} \mathrm{O}$ in aqueous methanol at room temperature, and subsequent acidification with $1 \mathrm{M}$ hydrochloric acid afforded compound 22. The coupling of compound 22 with ethyl 5-amino- $1 H$-indole-2-carboxylate in the presence of $\mathrm{POCl}_{3}$ and pyridine in $\mathrm{CH}_{2} \mathrm{Cl}_{2}$, and next reduction of $\mathrm{NO}_{2}$ with $\mathrm{H}_{2}$ (1 atm) in $\mathrm{MeOH}$ and ethyl acetate in the presence of $\mathrm{Pd} / \mathrm{C}$ yielded compound 23. Hydrolysis of ethyl ester with $\mathrm{LiOH} \cdot \mathrm{H}_{2} \mathrm{O}$ in aqueous ethanol at $40{ }^{\circ} \mathrm{C}$, and acidification of the resultant mixture with $1 \mathrm{M}$ hydrochloric acid afforded target compounds 7z.Compound 23 reacted with 2-methylcyclopropanecarboxylic acid in the presence of $\mathrm{POCl}_{3}$ and pyridine in $\mathrm{CH}_{2} \mathrm{Cl}_{2}$ leading to 24za. Reaction of 23 with 4-methylpiperazine-1-carbonyl chloride in the presence of pyridine and 4-dimethylaminopyridine in DMF afforded $\mathbf{2 4 z b}$. Compound 23 was coupled with 2-(2-chloroethoxy)acetic acid in the presence of $N$-ethoxycarbonyl-2-ethoxy-1,2-dihydroquinoline in THF, and the resultant product was treated with $\mathrm{NaH}$ in THF leading to 24zc. Target compounds 7za-7zc were synthesized from $\mathbf{2 4 z a - 2 4 z c}$ according to the procedure described for the preparation of $7 \mathbf{z}$.

The synthetic route to intermediates 11a-11n and 11r is shown in Scheme 5 according to relevant references [26]. 27a first reacted with diethyl oxalate in the presence ofLiHMDS in MTBE at $0{ }^{\circ} \mathrm{C}$ and the resultant mixture was acidified with hydrochloric acid $(1 \mathrm{M})$ to yield 28a. The cyclization of 28a with hydrazine hydrate in $\mathrm{EtOH}$ at $80{ }^{\circ} \mathrm{C}$ yielded 29a. The hydrolysis of 29a with $\mathrm{NaOH}$ in $\mathrm{EtOH}$ and $\mathrm{H}_{2} \mathrm{O}$ and acidification with $1 \mathrm{M}$ hydrochloric acid afforded 11a. The intermediates 11b-11n and 11r were synthesized from $\mathbf{2 7 b}-\mathbf{2 7 n}$ according to the procedure described for the preparation of 11a. 


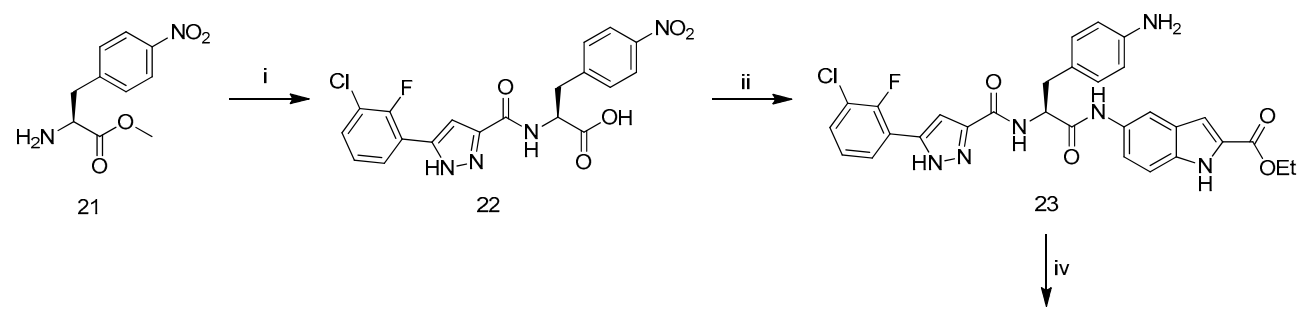

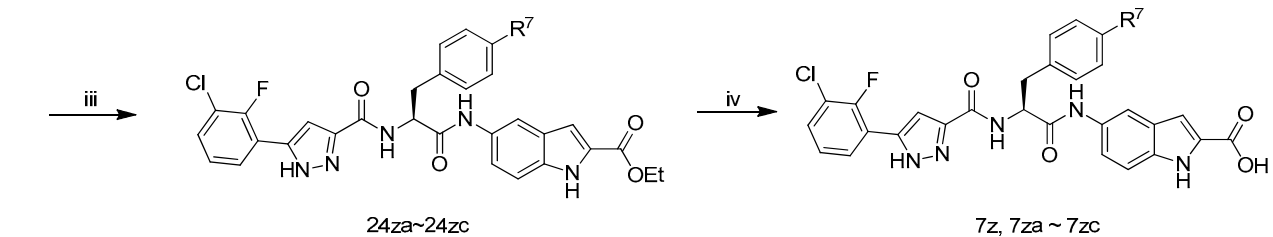

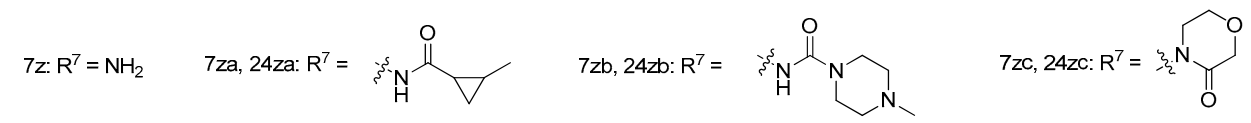

Scheme 4. Synthetic route of compounds 7z-7zc. Reagents and conditions: (i) (1) 11f, HOBT, EDCI, DIEA, DMF, r.t.; (2) $\mathrm{LiOH} \cdot \mathrm{H}_{2} \mathrm{O}, \mathrm{MeOH}, \mathrm{H}_{2} \mathrm{O}$, r.t.; (3) $1 \mathrm{M}$ hydrochloric acid; (ii) (1) ethyl 5-amino-1H-indole-2-carboxylate, HOBT, EDCI, DIEA, DMF, r.t.; (2) Pd/C, $\mathrm{H}_{2}, \mathrm{MeOH}$, EtOAc; (iii) for 24za: 2-Methylcyclopropanecarboxylic acid, $\mathrm{POCl}_{3}$, Pyridine, $\mathrm{CH}_{2} \mathrm{Cl}_{2},-10{ }^{\circ} \mathrm{C}$; for 24zb: 4-methylpiperazine-1-carbonyl chloride, Pyridine, DMAP, DMF; for 24zc: (1) 2-(2-chloroethoxy)acetic acid, EEDQ, THF; (2) NaH, THF; (iv) (1) $\mathrm{LiOH} \cdot \mathrm{H}_{2} \mathrm{O}, \mathrm{MeOH}, \mathrm{H}_{2} \mathrm{O}, 40{ }^{\circ} \mathrm{C}$; (2) $1 \mathrm{M}$ hydrochloric acid.
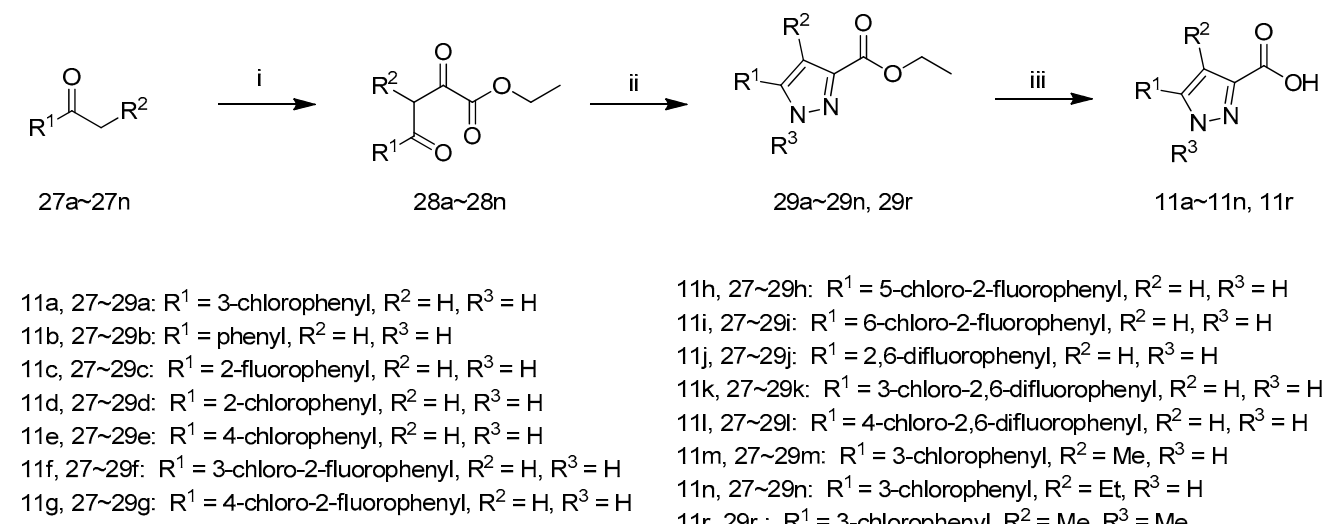

Scheme 5. Synthetic route of compounds 11a 11n and 11r. Reagents and conditions: (i) (1) LiHMDS, Diethyl oxalate, MTBE, $0{ }^{\circ} \mathrm{C}$; (2) $1 \mathrm{M}$ hydrochloric acid; (ii) for 29a-29n: hydrazine hydrate, $\mathrm{EtOH}, 80^{\circ} \mathrm{C}$; for 29r: Methylhydrazine sulfate, $\mathrm{EtOH}, 80^{\circ} \mathrm{C}$; (iii) (1) $\mathrm{NaOH}, \mathrm{EtOH}, \mathrm{H}_{2} \mathrm{O}$, r.t.; (2) $1 \mathrm{M}$ hydrochloric acid.

The synthetic route to intermediates $\mathbf{1 4 a - 1 4 f}$ and12 is depicted in Scheme 6 according to relevant references [18]. Compound 32 was prepared by the coupling of carboxylic acid 30 with amine 31 in the presence of $\mathrm{POCl}_{3}$ and pyridine in $\mathrm{CH}_{2} \mathrm{Cl}_{2}$ at $-10^{\circ} \mathrm{C}$. Removal of $\mathrm{N}$-Boc of 32 with hydrochloric acid in ethyl acetate yielded compound 12. The preparation of compound $\mathbf{1 4 a - 1 4 f}$ followed the procedure described for the preparation of compound 12. 

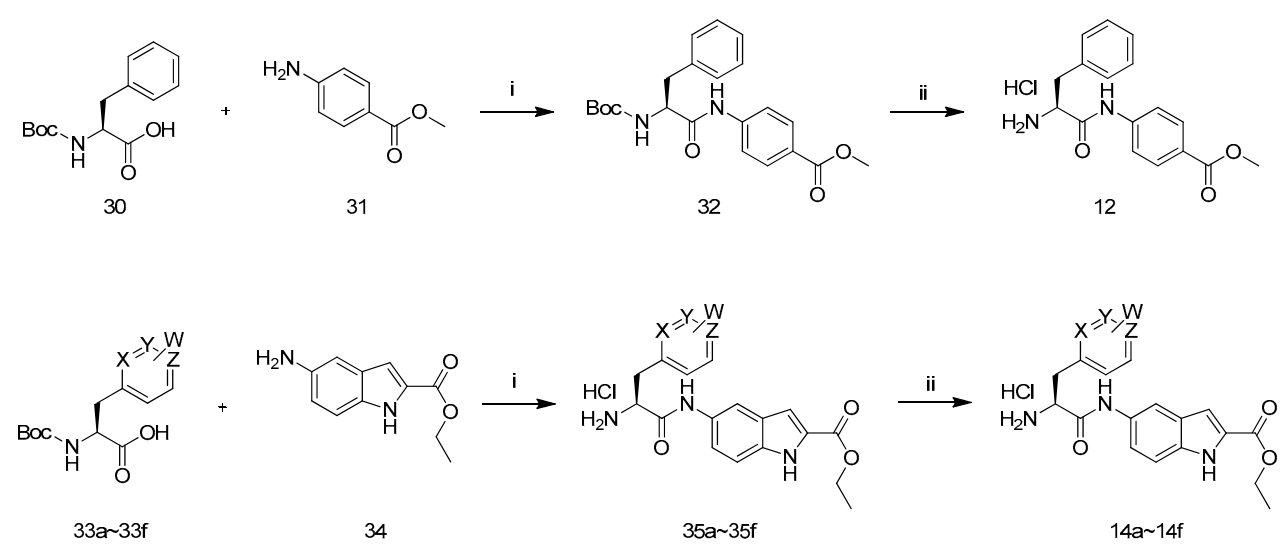

33a, 35a, 14a: $X=C, Y=C, Z=C, W$ : no substitution
33b, 35b, 14b: $X=C, Y=C, Z=C, W=4 F$ $33 \mathrm{~b}, 35 \mathrm{~b}, 14 \mathrm{~b}: X=C, Y=C, Z=C, W=4 F$
33c, 35c, $14 \mathrm{c}: X=C Y=C, Z=C, W=3-F$

33d, 35d, 14d: $X=C, Y=C, Z=N, W:$ no substitution 33e, 35e, 14e: $X=C, Y=N, Z=C, W:$ no substitution
33f, 35f, 14f: $X=N, Y=C, Z=C, W$ : no substitution

Scheme 6. Synthetic route of compounds 14a-14f and 12. Reagents and conditions: (i) $\mathrm{POCl}_{3}, \mathrm{Pyridine}$ $\mathrm{CH}_{2} \mathrm{Cl}_{2},-10{ }^{\circ} \mathrm{C}$; (ii) $\mathrm{HCl} / \mathrm{EtOAc}$.

\subsection{Biological Activity and Discussion}

\subsubsection{In Vitro Inhibition Activity Studies on FXIa}

In vitro FXIa affinity assay was used to examine the potency of $7 \mathbf{a}-7 \mathbf{z c}$ against FXIa. As the effects of compound 4, compound 3 and BMS-962212 (Figure 1) on FXIa activities were almost in the same degree (FXIa Ki $=0.7 \sim 3 \mathrm{~nm}$ ) and they were all reported by Bristol-Myers Squibb Company, so whichever one was chosen as a positive control for in vitro FXIa affinity assays and activated partial prothrombin time (aPTT) coagulation assays is reasonable. Taking these points into account, compound 4 was used as a positive control in both assays. As shown in Table 1, 7a, 7f, 7k, $7 \mathbf{m}$ showed better potency for FXIa's inhibition than others in series of $\mathbf{7 a}-\mathbf{7} \mathbf{n}$ with the same $\mathrm{P} 1^{\prime}, \mathrm{P2}$ 'moiety and scaffold. Furthermore, $7 \mathrm{~m}$ showed weaker potency for FXIa's inhibition than 7a but better potency than $\mathbf{7 n}$. Therefore, it can be inferred that $7 \mathbf{m}$ 's -Me is a relatively better $\mathrm{R}_{2}$ substitution than $\mathbf{7 a} \mathbf{s}-\mathrm{H}$ and $\mathbf{7 n}$ 's -Et for FXIa's inhibition. For further optimization, the P2' moiety in $7 \mathrm{f}, 7 \mathbf{k}$ and $\mathbf{7 m}$ was changed from the 4-aminobenzoic acid moiety to 5 -amino- $1 H$-indole-2-carboxylic acid moiety to give $\mathbf{7 o}, \mathbf{7 p}$ and $\mathbf{7 q}$, respectively, of which $\mathbf{7 o}$ possessed the best potency for FXIa's inhibition. Meanwhile, we also employed $7 r^{\prime}$ s inhibition potency of FXIa which is different from $\mathbf{7 q}$ at $R_{3}$ position (-Me substitution), and the results suggested that the $R_{3}$ substitution plays a minor role in the FXIa's inhibition. Based on above results, $7 \mathbf{o}$ was chosen for further modification and the P1'moiety was replaced by 4 other groups. It's indicated that replacement of $\mathrm{P}^{\prime}$ ' moiety on $\mathbf{7 \mathbf { o } ^ { \prime }}$ benzene with 4-fluorobenzo (7s) and 3-fluorobenzo (7t) improved the potency slightly $(7 \mathrm{~s}=930.49 \mathrm{~nm}, 7 \mathrm{t}=1.66 \mu \mathrm{m}, 7 \mathbf{o}=1.97 \mu \mathrm{m})$. The replacement of benzyl-type $\mathrm{P} 1^{\prime}$ moiety in $7 \mathbf{o}$ with 4-pyridine, 3-pyridine or 2-pyridine $(7 \mathbf{u}, 7 \mathbf{v}, 7 \mathbf{w}$, respectively) was not benefit for potency as $7 \mathbf{v}, 7 \mathbf{u}$, and $7 \mathbf{w}$ showed reduced potency than $7 \mathbf{o}(7 \mathbf{o}=1.97 \mu \mathrm{m}, 7 \mathbf{v}=3.52 \mu \mathrm{m}$, $7 \mathbf{u}=13.27 \mu \mathrm{m}, 7 \mathbf{w}=8.99 \mu \mathrm{m})$. The replacement of the P1' moiety with carboxamide $(7 \mathbf{x}, 7 \mathbf{y})$ was harmful for potency with 15 times reduction on potency $(7 \mathbf{o}=1.97 \mu \mathrm{m}, 7 \mathbf{x}=81.18 \mu \mathrm{m}, 7 \mathbf{y}=64.01 \mu \mathrm{m})$. At last, replacement of the $\mathrm{P} 1^{\prime}$ moiety in 7o with 2-methylcyclopropanecarboxamide (7za) obviously improved the potency for more than 20 times $(7 \mathbf{z a}=90.37 \mathrm{~nm}, 7 \mathbf{o}=1.97 \mu \mathrm{m})$. In addition, $7 \mathbf{z a}$ shows similar FXIa inhibitory potency as previously reported compound $\mathbf{4}(\mathbf{z z a}=90.37 \mathrm{~nm}, \mathbf{4}=23.48 \mathrm{~nm})$. 
Table 1. Results of in vitro inhibitory assay of 7a-7zc against FXIa (Ki).

\begin{tabular}{|c|c|c|c|c|c|c|c|}
\hline Compound & $\mathbf{R}_{\mathbf{1}}$ & $\mathbf{R}_{2}$ & $\mathbf{R}_{\mathbf{3}}$ & $X, Y, Z$ & $\mathbf{W}$ & $\mathbf{R}_{4}$ or $\mathbf{R}_{5}$ & $\mathbf{K i}^{\mathbf{a}}$ \\
\hline $7 a$ & 3-chlorophenyl & $\mathrm{H}$ & $\mathrm{H}$ & - & - & - & $46.66 \mu \mathrm{M}$ \\
\hline $7 b$ & phenyl & $\mathrm{H}$ & $\mathrm{H}$ & - & - & - & $>84.46 \mu \mathrm{M}$ \\
\hline $7 \mathrm{c}$ & 2-fluorophenyl & $\mathrm{H}$ & $\mathrm{H}$ & - & - & - & $>84.46 \mu \mathrm{M}$ \\
\hline $7 d$ & 2-chlorophenyl & $\mathrm{H}$ & $\mathrm{H}$ & - & - & - & $>84.46 \mu \mathrm{M}$ \\
\hline $7 e$ & 4-chlorophenyl & $\mathrm{H}$ & $\mathrm{H}$ & - & - & - & $>84.46 \mu \mathrm{M}$ \\
\hline $7 f$ & 3-chloro-2-fluorophenyl & $\mathrm{H}$ & $\mathrm{H}$ & - & - & - & $29.30 \mu \mathrm{M}$ \\
\hline $7 \mathrm{~g}$ & 4-chloro-2-fluorophenyl & $\mathrm{H}$ & $\mathrm{H}$ & - & - & - & $>84.46 \mu \mathrm{M}$ \\
\hline $7 \mathrm{~h}$ & 5-chloro-2-fluorophenyl & $\mathrm{H}$ & $\mathrm{H}$ & - & - & - & $>84.46 \mu \mathrm{M}$ \\
\hline $7 \mathbf{i}$ & 6-chloro-2-fluorophenyl & $\mathrm{H}$ & $\mathrm{H}$ & - & - & - & $>84.46 \mu \mathrm{M}$ \\
\hline $7 \mathbf{j}$ & 2,6-difluorophenyl & $\mathrm{H}$ & $\mathrm{H}$ & - & - & - & $>84.46 \mu \mathrm{M}$ \\
\hline $7 \mathrm{k}$ & 3-chloro-2,6-difluorophenyl & $\mathrm{H}$ & $\mathrm{H}$ & - & - & - & $28.88 \mu \mathrm{M}$ \\
\hline 71 & 4-chloro-2,6-difluorophenyl & $\mathrm{H}$ & $\mathrm{H}$ & - & - & - & $>84.46 \mu \mathrm{M}$ \\
\hline $7 \mathrm{~m}$ & 3-chlorophenyl & $\mathrm{Me}$ & $\mathrm{H}$ & - & - & - & $37.15 \mu \mathrm{M}$ \\
\hline $7 \mathbf{n}$ & 3-chlorophenyl & Et & $\mathrm{H}$ & - & - & - & $>84.46 \mu \mathrm{M}$ \\
\hline 70 & 3-chloro-2-fluorophenyl & $\mathrm{H}$ & $\mathrm{H}$ & $\mathrm{C}, \mathrm{C}, \mathrm{C}$ & - & - & $1.97 \mu \mathrm{M}$ \\
\hline $7 p$ & 3-chloro-2,6-difluorophenyl & $\mathrm{H}$ & $\mathrm{H}$ & $\mathrm{C}, \mathrm{C}, \mathrm{C}$ & - & - & $8.40 \mu \mathrm{M}$ \\
\hline $7 q$ & 3-chlorophenyl & $\mathrm{Me}$ & $\mathrm{H}$ & $\mathrm{C}, \mathrm{C}, \mathrm{C}$ & - & - & $8.94 \mu \mathrm{M}$ \\
\hline $7 \mathrm{r}$ & 3-chlorophenyl & $\mathrm{Me}$ & $\mathrm{Me}$ & $\mathrm{C}, \mathrm{C}, \mathrm{C}$ & - & - & $11.43 \mu \mathrm{M}$ \\
\hline $7 \mathrm{~s}$ & 3-chloro-2-fluorophenyl & $\mathrm{H}$ & $\mathrm{H}$ & $\mathrm{C}, \mathrm{C}, \mathrm{C}$ & $4-\mathrm{F}$ & - & $930.49 \mathrm{nM}$ \\
\hline $7 \mathrm{t}$ & 3-chloro-2-fluorophenyl & $\mathrm{H}$ & $\mathrm{H}$ & $\mathrm{C}, \mathrm{C}, \mathrm{C}$ & $3-\mathrm{F}$ & - & $1.66 \mu \mathrm{M}$ \\
\hline $7 \mathbf{u}$ & 3-chloro-2-fluorophenyl & $\mathrm{H}$ & $\mathrm{H}$ & $\mathrm{C}, \mathrm{C}, \mathrm{N}$ & - & - & $13.27 \mu \mathrm{M}$ \\
\hline $7 \mathbf{v}$ & 3-chloro-2-fluorophenyl & $\mathrm{H}$ & $\mathrm{H}$ & $\mathrm{C}, \mathrm{N}, \mathrm{C}$ & - & - & $3.52 \mu \mathrm{M}$ \\
\hline $7 w$ & 3-chloro-2-fluorophenyl & $\mathrm{H}$ & $\mathrm{H}$ & $\mathrm{N}, \mathrm{C}, \mathrm{C}$ & - & - & $8.99 \mu \mathrm{M}$ \\
\hline $7 x$ & - & - & - & - & - & & $81.18 \mu \mathrm{M}$ \\
\hline $7 y$ & - & - & - & - & - & $\mathrm{R}_{4}: \xi_{2}^{\mathrm{N}}$ & $64.01 \mu \mathrm{M}$ \\
\hline $7 z$ & - & - & - & - & - & $\mathrm{R}_{5}:-\mathrm{NH}_{2}$ & $4.10 \mu \mathrm{M}$ \\
\hline $7 z a$ & - & - & - & - & - & & $90.37 \mathrm{nM}$ \\
\hline $7 \mathrm{zb}$ & - & - & - & - & - & $\mathrm{H}_{\mathrm{N}}$ & $1.94 \mu \mathrm{M}$ \\
\hline $7 \mathrm{zc}$ & - & - & - & - & - & $R_{5}:{ }^{2 "} T$ & $4.82 \mu \mathrm{M}$ \\
\hline $4^{b}$ & - & - & - & - & - & - & $23.48 \mathrm{nM}$ \\
\hline
\end{tabular}

${ }^{\mathrm{a}} \mathrm{Ki}=\mathrm{IC}_{50} /(1+[\mathrm{S}] / \mathrm{Km}) ;[\mathrm{S}]: 435 \mu \mathrm{M}, \mathrm{Km}: 395 \mu \mathrm{M}, \mathrm{Ki}=\mathrm{IC}_{50} / 1.11$; ${ }^{\mathrm{b}}$ Reported value for compound 4: $\mathrm{Ki}=3.0 \mathrm{nM}$ against FXIa [18].

\subsubsection{Activated Partial Prothrombin Time (aPTT) In Vitro Coagulation Assays}

In order to assess the in vitro coagulation activity of compound 7za, activated partial prothrombin time (aPTT) of $\mathbf{7 z a}$ and compound 4 was compared. As indicated in Table 2, 7za showed good in vitro coagulation activity with $1.5 \times$ aPTT value of $43.33 \mu \mathrm{M}$ in rabbit plasma.

Table 2. The anticoagulant activity of 7za.

\begin{tabular}{cc}
\hline Compound & $\mathbf{1 . 5} \times$ aPTT $(\mu \mathrm{M})$ (Rabbit) \\
\hline $7 \mathrm{za}$ & 43.33 \\
$\mathbf{4}$ & 3.79 \\
\hline
\end{tabular}




\subsection{Molecular Model Studies on the Interaction of Compound 7za with FXIa}

Molecular docking method was used to study the binding mode of compound 7za in the active site of FXIa. Two different binding modes of compound 7za with FXIa were obtained (Figure 5a,b). Superposition of these two binding modes with the known compound 3 (Figure 5c,d) showed that 7za in the second binding mode and known compound $\mathbf{3}$ overlay well (Figure 5d), indicating that this kind of binding model of $7 \mathbf{z a}$ with FXIa is more reasonable (Figure 5b). As designated, the 5-(3-chloro-2-fluorophenyl)-1H-pyrazole moiety is located deeply inS1 pocket of FXIa with the $\mathrm{Cl}$ atom forming an interaction with Tyr228, and the carbonyl group of 5-(3-chloro-2-fluorophenyl)-1H-pyrazole-3-carboxamide is well positioned within the oxyanion hole by forming key hydrogen bonds with Gly193 residues which is similar to the binding model of compound 3 with FXIa (Figure 5d). Furthermore, the 2-methylcyclopropanecarboxamide group of 7za makes 2 direct hydrogen bonds with Tyr58B and Thr35 in the FXIa backbone, making 7za binds to FXIa in a highly efficient manner (Figure 5b).

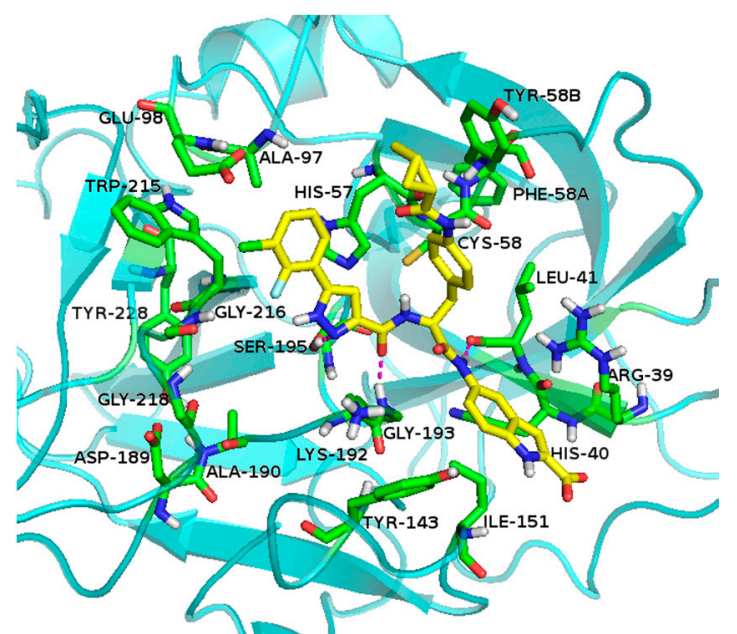

(a)

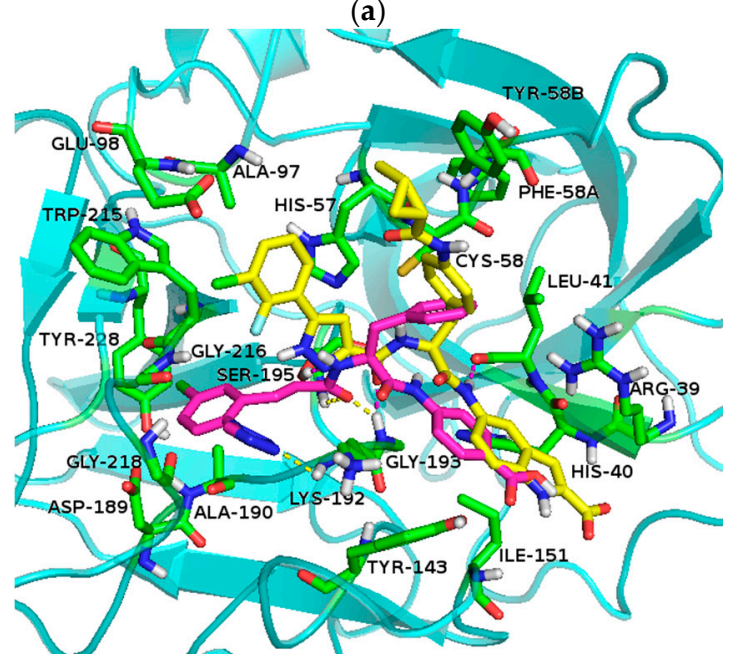

(c)

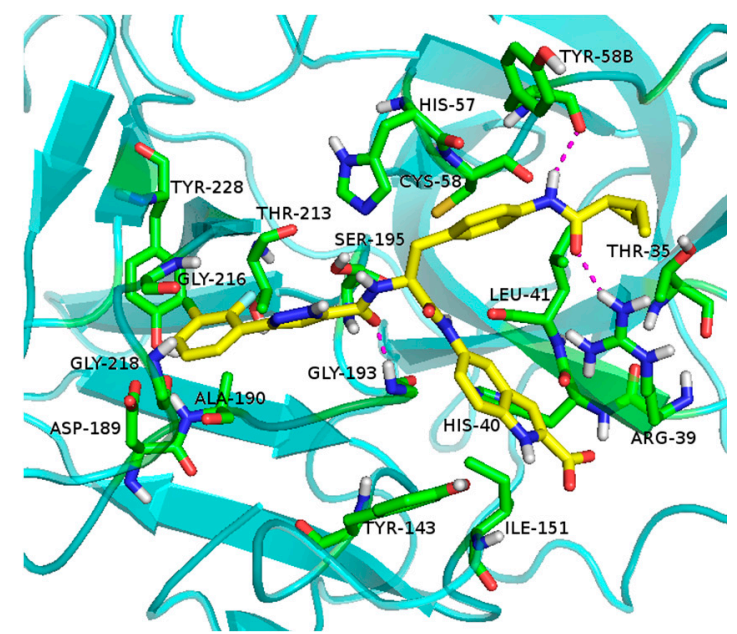

(b)

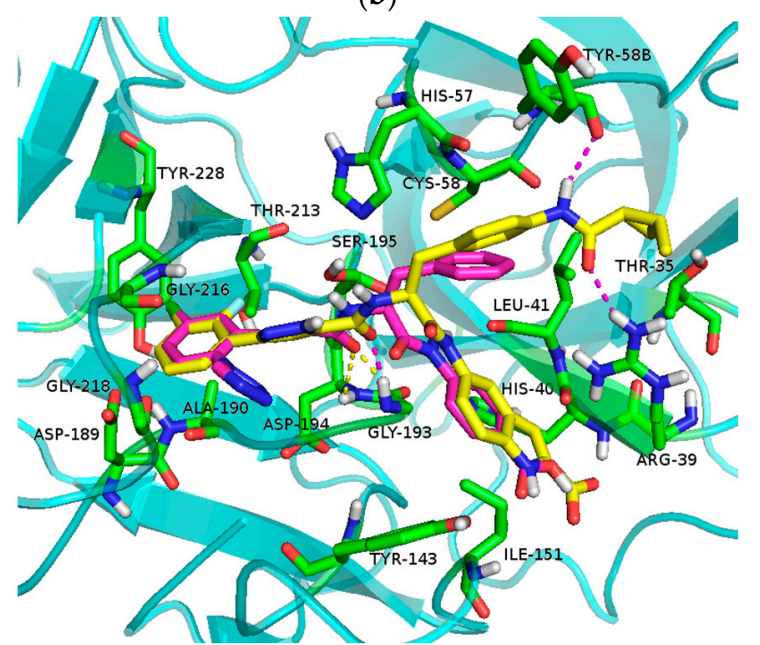

(d)

Figure 5. (a) Molecular model 1 of 7za in active site of FXIa; (b) Molecular model 2 of 7za in active site of FXIa; (c) Superposition of molecular mode 1 of 7za with compound 3 (7za: yellow, compound 3: purple); (d) Superposition of molecular mode 2 of $7 z a$ with compound 3 (7za: yellow, compound 3: purple). 


\section{Materials and Methods}

\subsection{General Information}

Reagents and solvents were purchased from commercial suppliers and used without further purification. Reactions were monitored by thin layer chromatography. ${ }^{1} \mathrm{H}-\mathrm{NMR}$ spectra $(400 \mathrm{MHz})$ and ${ }^{13} \mathrm{C}-\mathrm{NMR}(100 \mathrm{MHz})$ were recorded for DMSO- $\mathrm{d}_{6}$ solutions on a Bruker spectrometer (Bruker, Billerica, MA, USA). MS were measured on a Finnigan LCQ Mass (Thermo Fisher Scientific, Waltham, MA, USA). HRMS were measured on a TOF LC/MS instrument (Agilent Technologies, Santa Clara, CA, USA).

\subsection{Chemistry}

Ethyl 2,4-dioxo-4-phenylbutanoate (28b): To a stirred solution of acetophenone (27b) $(2.0 \mathrm{~g}, 16.5 \mathrm{mmol})$ in MTBE (30 mL) was added lithium hexamethyldisilazide $(1.3 \mathrm{M}, 12.7 \mathrm{~mL}, 16.5 \mathrm{mmol})$ dropwise at $0^{\circ} \mathrm{C}$; After addition, the reaction mixture was stirred at $0^{\circ} \mathrm{C}$ for $0.5 \mathrm{~h}$ and diethyl oxalate $(3.0 \mathrm{~g}, 20.8 \mathrm{mmol})$ was added dropwise. Then, the mixture was stirred at room temperature overnight. TLC analysis showed reaction was complete and the reaction mixture was extracted with $\mathrm{H}_{2} \mathrm{O}(20 \mathrm{~mL})$. The aqueous layer was separated, acidified by hydrochloric acid $(1 \mathrm{M})$ to $\mathrm{pH} 6$ and extracted by ethyl acetate $(10 \mathrm{~mL} \times 2)$. The combined organic layer was concentrated in vacuum to give $\mathbf{2 8 b}$ as yellow oil, which was used for next step without further purification $(3.4 \mathrm{~g}, 92.7 \%$ yield).

Ethyl3-phenyl-1H-pyrazole-5-carboxylate (29b): To a solution of $\mathbf{2 8 b}$ (3.4 g, $15.4 \mathrm{mmol})$ in EtOH (15 mL) was added hydrazine hydrate $(1.2 \mathrm{~g}, 24.0 \mathrm{mmol})$ and the mixture was stirred at $50{ }^{\circ} \mathrm{C}$ for $2 \mathrm{~h}$ when TLC analysis indicated completion of reaction. Then the reaction mixture was evaporated to get crude $\mathbf{2 9 b}$ as brown oil, which was used for next step without further purification ( $2.6 \mathrm{~g}, 77.9 \%$ yield).

5-Phenyl-1H-pyrazole-3-carboxylic acid (11b): To a solution of compound 29b (2.6 g, $9.1 \mathrm{mmol})$ in $\mathrm{MeOH}$ $(30 \mathrm{~mL})$ and $\mathrm{H}_{2} \mathrm{O}(15 \mathrm{~mL})$ was added $\mathrm{LiOH} \cdot \mathrm{H}_{2} \mathrm{O}(0.5 \mathrm{~g}, 20.0 \mathrm{mmol})$ and the mixture was stirred at $70{ }^{\circ} \mathrm{C}$ for $8 \mathrm{~h}$. The reaction mixture was evaporated and $\mathrm{H}_{2} \mathrm{O}(15 \mathrm{~mL})$ was added, then acidified by hydrochloric acid $(1 \mathrm{M})$ to $\mathrm{pH}$ 3. The suspension was filtered and washed by $\mathrm{H}_{2} \mathrm{O}(10 \mathrm{~mL})$, dried at $50{ }^{\circ} \mathrm{C}$ for $4 \mathrm{~h}$ to afford $\mathbf{1 1 b}$ as a white solid $\left(2.1 \mathrm{~g}, 89.5 \%\right.$ yield), m.p.: $227-229{ }^{\circ} \mathrm{C}$, decomposition. ${ }^{1} \mathrm{H}-\mathrm{NMR}: \delta 13.39$ (s, 1H), 7.83 (m, 2H), 7.41-7.45 (m, 2H), 7.31-7.35 (m, 1H), 7.18(s, 1H). HRMS (ESI) calcd. For $\mathrm{C}_{10} \mathrm{H}_{8} \mathrm{ClN}_{2} \mathrm{O}_{2}{ }^{+}:[\mathrm{M}+\mathrm{H}]^{+} \mathrm{m} / z$ : 189.0659, found: 189.0659. The ${ }^{1} \mathrm{H}-\mathrm{NMR}$ data were in good agreement with those reported [26].

Compounds 11a, 11r and 11c-11n were synthesized according to the procedure described for the preparation of $\mathbf{1 1 b}$.

5-(3-Chlorophenyl)-1H-pyrazole-3-carboxylic acid (11a): white solid product (1.5 g, 47.9\% yield), m.p.: 219-221 ${ }^{\circ} \mathrm{C}$, decomposition. ${ }^{1} \mathrm{H}-\mathrm{NMR}: \delta$ 13.85-13.15 (m, 2H), $7.90(\mathrm{~m}, 1 \mathrm{H}), 7.82-7.80(\mathrm{~d}, J=7.6 \mathrm{~Hz}, 1 \mathrm{H})$, 7.47-7.37 (m, 2H), $7.29(\mathrm{~s}, 1 \mathrm{H})$. HRMS (ESI) calcd. For $\mathrm{C}_{10} \mathrm{H}_{9} \mathrm{~N}_{2} \mathrm{O}_{2}{ }^{+}:[\mathrm{M}+\mathrm{H}]^{+} \mathrm{m} / z$ : 223.0269, found: 223.0268. The ${ }^{1} \mathrm{H}-\mathrm{NMR}$ data were in good agreement with those reported [26].

3-(2-Fluorophenyl)-1H-pyrazole-5-carboxylic acid (11c): white solid product (2.3 g, 77.0\% yield), m.p.: 232-234 ${ }^{\circ} \mathrm{C}$, decomposition. ${ }^{1} \mathrm{H}-\mathrm{NMR}: \delta$ 13.84-13.52 (m, 2H), 7.94-7.91 (m, 1H), 7.43-7.38 (m, 1H), 7.34-7.27 (m, 2H), 7.05-7.04 (d, $J=3.6 \mathrm{~Hz}, 1 \mathrm{H})$. HRMS (ESI) calcd. For $\mathrm{C}_{10} \mathrm{H}_{8} \mathrm{FN}_{2} \mathrm{O}_{2}{ }^{+}:[\mathrm{M}+\mathrm{H}]^{+} \mathrm{m} / z$ : 207.0564, found: 207.0563 [27].

3-(2-Chlorophenyl)-1H-pyrazole-5-carboxylic acid (11d): white solid product (1.8g, 62.5\% yield), m.p.: 229-231 ${ }^{\circ} \mathrm{C}$, decomposition. ${ }^{1} \mathrm{H}-\mathrm{NMR}: \delta 13.64-13.49(\mathrm{~m}, 2 \mathrm{H}), 7.74(\mathrm{~s}, 1 \mathrm{H}), 7.57-7.55(\mathrm{~m}, 1 \mathrm{H}), 7.44-7.41$ $(\mathrm{m}, 2 \mathrm{H}), 7.12(\mathrm{~s}, 1 \mathrm{H})$. HRMS (ESI) calcd. For $\mathrm{C}_{10} \mathrm{H}_{8} \mathrm{ClN}_{2} \mathrm{O}_{2}{ }^{+}:[\mathrm{M}+\mathrm{H}]^{+} m / z: 223.0269$, found: 223.0268 [27].

3-(4-Chlorophenyl)-1H-pyrazole-5-carboxylic acid (11e): white solid product (1.5 g, 52.1\% yield), m.p.: 240-242 ${ }^{\circ} \mathrm{C}$, decomposition. ${ }^{1} \mathrm{H}-\mathrm{NMR}: \delta 13.86-13.64(\mathrm{~m}, 2 \mathrm{H}), 7.86-7.84(\mathrm{~d}, J=8.4 \mathrm{~Hz}, 2 \mathrm{H}), 7.49-7.47$ $(\mathrm{d}, J=8.4 \mathrm{~Hz}, 2 \mathrm{H}), 7.04(\mathrm{~s}, 1 \mathrm{H})$. HRMS (ESI) calcd. For $\mathrm{C}_{10} \mathrm{H}_{8} \mathrm{ClN}_{2} \mathrm{O}_{2}{ }^{+}:[\mathrm{M}+\mathrm{H}]^{+} \mathrm{m} / z: 223.0269$, found: 223.0269. The ${ }^{1} \mathrm{H}-\mathrm{NMR}$ data were in good agreement with those reported [26]. 
3-(3-Chloro-2-fluorophenyl)-1H-pyrazole-5-carboxylic acid (11f): white solid product (2.0 g, 71.7\% yield), m.p.: $236-238{ }^{\circ} \mathrm{C}$, decomposition. ${ }^{1} \mathrm{H}-\mathrm{NMR}: \delta 13.77(\mathrm{~m}, 1 \mathrm{H}), 7.92-7.88(\mathrm{~m}, 1 \mathrm{H}), 7.56-7.52(\mathrm{~m}, 1 \mathrm{H})$, 7.30-7.26 (m, 1H), 6.98-6.97 (d, J = 4.0 Hz, 1H). HRMS (ESI) calcd. For $\mathrm{C}_{10} \mathrm{H}_{7} \mathrm{ClFN}_{2} \mathrm{O}_{2}{ }^{+}:[\mathrm{M}+\mathrm{H}]^{+} m / z$ : 241.0175, found: 241.0173 .

3-(4-Chloro-2-fluorophenyl)-1H-pyrazole-5-carboxylic acid (11g): white solid product (1.9 g, 68.1\% yield), m.p.: $234-236{ }^{\circ} \mathrm{C}$, decomposition. ${ }^{1} \mathrm{H}-\mathrm{NMR}: \delta 13.07(\mathrm{~s}, 1 \mathrm{H}), 7.98-7.93(\mathrm{t}, J=8.4 \mathrm{~Hz}, 2 \mathrm{H}), 7.47-7.44$ (qd, $J=2 \mathrm{~Hz}, 1 \mathrm{H}), 7.31-7.28(\mathrm{qd}, J=2 \mathrm{~Hz}, 1 \mathrm{H}), 6.66-6.65(\mathrm{~d}, J=4.4 \mathrm{~Hz}, 1 \mathrm{H})$. HRMS (ESI) calcd. For $\mathrm{C}_{10} \mathrm{H}_{7} \mathrm{ClFN}_{2} \mathrm{O}_{2}{ }^{+}:[\mathrm{M}+\mathrm{H}]^{+} m / z: 241.0175$, found: 241.0172 .

3-(5-Chloro-2-fluorophenyl)-1H-pyrazole-5-carboxylic acid (11h): white solid product (1.5 g, 53.8\% yield), m.p.: 229-231 ${ }^{\circ} \mathrm{C}$, decomposition. ${ }^{1} \mathrm{H}-\mathrm{NMR}: \delta 14.11-13.42(\mathrm{~m}, 2 \mathrm{H}), 7.97-7.95(\mathrm{~m}, 1 \mathrm{H}), 7.47-7.36(\mathrm{~m}, 2 \mathrm{H})$, 7.10-7.05 (m, 1H). HRMS (ESI) calcd. For $\mathrm{C}_{10} \mathrm{H}_{7} \mathrm{ClFN}_{2} \mathrm{O}_{2}{ }^{+}:[\mathrm{M}+\mathrm{H}]^{+} m / z: 241.0175$, found: 241.0172.

3-(2-Chloro-6-fluorophenyl)-1H-pyrazole-5-carboxylic acid (11i): white solid product (1.6 g, 57.4\% yield), m.p.: $182-184{ }^{\circ} \mathrm{C}$, decomposition. ${ }^{1} \mathrm{H}-\mathrm{NMR}: \delta 14.13-14.06(\mathrm{~m}, 1 \mathrm{H}), 13.72-13.48(\mathrm{~m}, 1 \mathrm{H}), 7.49-7.46$ $(\mathrm{m}, 2 \mathrm{H}), 7.35(\mathrm{~m}, 1 \mathrm{H}), 6.91(\mathrm{~s}, 1 \mathrm{H})$. HRMS (ESI) calcd. For $\mathrm{C}_{10} \mathrm{H}_{7} \mathrm{ClFN}_{2} \mathrm{O}_{2}{ }^{+}:[\mathrm{M}+\mathrm{H}]^{+} m / z: 241.0175$, found: 241.0170 [28].

3-(2,6-Difluorophenyl)-1H-pyrazole-5-carboxylic acid (11j): white solid product (1.6 g, 55.7\% yield), m.p.: 232-334 ${ }^{\circ} \mathrm{C}$, decomposition. ${ }^{1} \mathrm{H}-\mathrm{NMR}: \delta 14.08-13.05(\mathrm{~m}, 2 \mathrm{H}), 7.53-7.46(\mathrm{~m}, 1 \mathrm{H}), 7.25-7.21(\mathrm{~m}, 2 \mathrm{H}), 6.98$ (s, 1H). HRMS (ESI) calcd. For $\mathrm{C}_{10} \mathrm{H}_{7} \mathrm{~F}_{2} \mathrm{~N}_{2} \mathrm{O}_{2}{ }^{+}:[\mathrm{M}+\mathrm{H}]^{+} \mathrm{m} / z$ : 225.0470, found: 241.0465.

3-(3-Chloro-2,6-difluorophenyl)-1H-pyrazole-5-carboxylic acid (11k): white solid product (1.2 g, 44.2\% yield), m.p.: 233-235 ${ }^{\circ} \mathrm{C}$, decomposition. ${ }^{1} \mathrm{H}-\mathrm{NMR}: \delta 14.17(\mathrm{~s}, 1 \mathrm{H}), 7.72-7.67(\mathrm{~m}, 1 \mathrm{H}), 7.33-7.29(\mathrm{~m}, 1 \mathrm{H}), 7.02$ (s, 1H). HRMS (ESI) calcd. For $\mathrm{C}_{10} \mathrm{H}_{6} \mathrm{ClF}_{2} \mathrm{~N}_{2} \mathrm{O}_{2}{ }^{+}:[\mathrm{M}+\mathrm{H}]^{+} m / z: 259.0080$, found: 259.0074.

3-(4-Chloro-2,6-difluorophenyl)-1H-pyrazole-5-carboxylic acid (111): white solid product (1.6 g, 58.9\% yield), m.p.: $238-240{ }^{\circ} \mathrm{C}$, decomposition. ${ }^{1} \mathrm{H}-\mathrm{NMR}: \delta 13.64(\mathrm{~s}, 1 \mathrm{H}), 7.51-7.49(\mathrm{~d}, J=8.0 \mathrm{~Hz}, 2 \mathrm{H}), 6.99(\mathrm{~s}, 1 \mathrm{H})$. HRMS (ESI) calcd. For $\mathrm{C}_{10} \mathrm{H}_{6} \mathrm{ClF}_{2} \mathrm{~N}_{2} \mathrm{O}_{2}{ }^{+}:[\mathrm{M}+\mathrm{H}]^{+} m / z: 259.0080$, found: 259.0078.

5-(3-Chlorophenyl)-4-methyl-1H-pyrazole-3-carboxylic acid (11m): white solid product (1.1 g, 39.2\% yield), m.p.: $226-228{ }^{\circ} \mathrm{C}$, decomposition. ${ }^{1} \mathrm{H}-\mathrm{NMR}: \delta 13.64-13.57(\mathrm{~m}, 2 \mathrm{H}), 7.66(\mathrm{~s}, 1 \mathrm{H}), 7.63-7.57(\mathrm{~m}, 1 \mathrm{H})$, 7.51-7.42 (m, 2H), 2.39(s, 3H). HRMS (ESI) calcd. For $\mathrm{C}_{11} \mathrm{H}_{10} \mathrm{ClN}_{2} \mathrm{O}_{2}{ }^{+}:[\mathrm{M}+\mathrm{H}]^{+} m / z: 237.0425$, found: 237.0424.

5-(3-Chlorophenyl)-4-ethyl-1H-pyrazole-3-carboxylic acid (11n): white solid product ( $0.2 \mathrm{~g}, 7.3 \%$ yield), m.p.: $236-238^{\circ} \mathrm{C}$, decomposition. ${ }^{1} \mathrm{H}-\mathrm{NMR}: \delta 13.43(\mathrm{~s}, 1 \mathrm{H}), 7.58(\mathrm{~s}, 1 \mathrm{H}), 7.53-7.43(\mathrm{~m}, 3 \mathrm{H}), 2.82-2.76$ $(\mathrm{qd}, J=7.2 \mathrm{~Hz}, 2 \mathrm{H}), 1.12-1.08(\mathrm{~m}, 3 \mathrm{H})$. HRMS (ESI) calcd. For $\mathrm{C}_{12} \mathrm{H}_{12} \mathrm{ClN}_{2} \mathrm{O}_{2}{ }^{+}:[\mathrm{M}+\mathrm{H}]^{+} \mathrm{m} / z: 251.0582$, found: 251.0577 .

5-(3-Chlorophenyl)-1,4-dimethyl-1H-pyrazole-3-carboxylic acid (11r): white solid product $(1.1 \mathrm{~g}, 37.0 \%$ yield), m.p.: $147-149{ }^{\circ} \mathrm{C}$, decomposition. ${ }^{1} \mathrm{H}-\mathrm{NMR}: \delta 12.52(\mathrm{~s}, 1 \mathrm{H}), 7.56-7.54(\mathrm{~m}, 3 \mathrm{H}), 7.41-7.39$ $(\mathrm{m}, 1 \mathrm{H}), 3.74(\mathrm{~s}, 3 \mathrm{H}), 2.10(\mathrm{~s}, 3 \mathrm{H})$. The structure was confirmed by NOESY.HRMS (ESI) calcd. For $\mathrm{C}_{12} \mathrm{H}_{12} \mathrm{ClN}_{2} \mathrm{O}_{2}{ }^{+}:[\mathrm{M}+\mathrm{H}]^{+} \mathrm{m} / z: 251.0582$, found: 251.0575.

(S)-Methyl-4-(2-((tert-butoxycarbonyl)amino)-3-phenylpropanamido)benzoate (32): To a stirred mixture of Boc-Phe-OH (30) (10.0 g, 37.7mmol), methyl 4-aminobenzoate (31) $(5.7 \mathrm{~g}, 37.7 \mathrm{mmol})$ and pyridine $(10 \mathrm{~mL})$ in $\mathrm{CH}_{2} \mathrm{Cl}_{2}(100 \mathrm{~mL})$ at $-10{ }^{\circ} \mathrm{C}$ was added $\mathrm{POCl}_{3}(5.8 \mathrm{~g}, 37.7 \mathrm{mmol})$ dropwise.After addition, the reaction mixture was stirred at $0{ }^{\circ} \mathrm{C}$ for $2 \mathrm{~h}$ when TLC analysis indicated completion of reaction, then $\mathrm{H}_{2} \mathrm{O}(20 \mathrm{~mL})$ was added and the organic layer was separated, washed by hydrochloric acid $(1 \mathrm{M}, 20 \mathrm{~mL})$, dried by $\mathrm{Na}_{2} \mathrm{SO}_{4}$, filtered. The filtrate was evaporated in vacuum to get crude 32 as a yellow solid, which was used for next step without further purification (11.6 g, 77.3\% yield).

(S)-Methyl-4-(2-amino-3-phenylpropanamido)benzoate hydrochloride (12): To a solution of compound 32 $(11.5 \mathrm{~g}, 28.9 \mathrm{mmol})$ in ethyl acetate $(50 \mathrm{~mL})$ was added hydrochloric/ethyl acetate $(50 \mathrm{~mL}$, saturated 
solution), and the mixture was stirred at room temperature overnight.Then TLC analysis showed reaction was complete. The suspension was filtered and the filter cake was washed by ethyl acetate $(20 \mathrm{~mL})$, dried at $50{ }^{\circ} \mathrm{C}$ for $4 \mathrm{~h}$ to afford 12 as a pink solid $\left(8.2 \mathrm{~g}, 84.3 \%\right.$ yield), m.p.: $127-129{ }^{\circ} \mathrm{C}$. ${ }^{1} \mathrm{H}-\mathrm{NMR}: \delta 11.27(\mathrm{~s}, 1 \mathrm{H}), 8.45(\mathrm{~s}, 3 \mathrm{H}), 7.93-7.91(\mathrm{~d}, J=8.4 \mathrm{~Hz}, 2 \mathrm{H}), 7.73-7.71(\mathrm{~d}, J=8.8 \mathrm{~Hz}, 2 \mathrm{H})$, 7.32-7.23 (m, 5H), $4.34(\mathrm{~m}, 1 \mathrm{H}), 3.81(\mathrm{~s}, 3 \mathrm{H}), 3.24-3.12(\mathrm{~m}, 2 \mathrm{H})$. ESI-MS $(m / z)=299.09[\mathrm{M}+\mathrm{H}]^{+}$.

(S)-Ethyl 5-(2-((tert-butoxycarbonyl)amino)-3-phenylpropanamido)-1H-indole-2-carboxylate (35a): To a mixture of Boc-Phe-OH (33a) (5 g, $18.9 \mathrm{mmol}$ ), ethyl 5-amino- $1 \mathrm{H}$-indole-2-carboxylate (34) (3.9 g, $18.9 \mathrm{mmol})$ and pyridine $(5 \mathrm{~mL})$ in $\mathrm{CH}_{2} \mathrm{Cl}_{2}(50 \mathrm{~mL})$ at $-10{ }^{\circ} \mathrm{C}$ was added $\mathrm{POCl}_{3}(2.9 \mathrm{~g}, 18.9 \mathrm{mmol})$ dropwise. After addition, the reaction mixture was stirred at $-10{ }^{\circ} \mathrm{C}$ for $2 \mathrm{~h}$ when TLC analysis indicated completion of reaction, then $\mathrm{H}_{2} \mathrm{O}(10 \mathrm{~mL})$ was added and the organic layer was separated, washed by hydrochloric acid $(1 \mathrm{M}, 10 \mathrm{~mL})$, dried by $\mathrm{Na}_{2} \mathrm{SO}_{4}$, filtered. The filtrate was evaporated in vacuum to get crude $35 \mathrm{a}$ as a brown solid, which was used for next step without further purification (6.6 $\mathrm{g}, 77.6 \%$ yield).

(S)-Ethyl 5-(2-amino-3-phenylpropanamido)-1H-indole-2-carboxylate hydrochloride (14a): To a solution of compound 35a $(6.5 \mathrm{~g}, 14.4 \mathrm{mmol})$ in ethyl acetate $(15 \mathrm{~mL})$ was added hydrochloric/ethyl acetate (30 mL, saturated solution), and the mixture was stirred at room temperature overnight. Then TLC analysis showed reaction was complete.The suspension was filtered and the filter cake was washed by ethyl acetate $(20 \mathrm{~mL})$ and dried at $50{ }^{\circ} \mathrm{C}$ for $4 \mathrm{~h}$ to afford $14 \mathrm{a}$ as a grey solid $(4.9 \mathrm{~g}, 87.7 \%$ yield), m.p.: 135-137 ${ }^{\circ} \mathrm{C}$, decomposition. ${ }^{1} \mathrm{H}-\mathrm{NMR}: \delta 11.86(\mathrm{~s}, 1 \mathrm{H}), 10.46(\mathrm{~s}, 1 \mathrm{H}), 8.36-8.32(\mathrm{~m}, 4 \mathrm{H}), 7.91(\mathrm{~s}, 1 \mathrm{H})$, 7.33-7.12 (m, 8H), 4.35-4.29 (m, 2H), $4.19(\mathrm{~m}, 1 \mathrm{H}), 3.13-3.08(\mathrm{~m}, 2 \mathrm{H}), 1.34-1.31(\mathrm{~m}, 3 \mathrm{H})$. ESI-MS $(\mathrm{m} / \mathrm{z})=$ $352.10[\mathrm{M}+1]^{+}[18]$. of $14 a$.

Compounds $\mathbf{1 4 b} \sim \mathbf{1 4 f}$ were synthesized according to the procedure described for the preparation

(S)-Ethyl5-(2-amino-3-(4-fluorophenyl)propanamido)-1H-indole-2-carboxylatehydrochloride (14b): grey solid product $\left(4.0 \mathrm{~g}, 52.3 \%\right.$ yield), m.p.: $243-245^{\circ} \mathrm{C}$, decomposition. ${ }^{1} \mathrm{H}-\mathrm{NMR}: \delta 11.85(\mathrm{~s}, 1 \mathrm{H}), 10.84(\mathrm{~s}, 1 \mathrm{H})$, $8.45(\mathrm{~s}, 2 \mathrm{H}), 7.96(\mathrm{~s}, 1 \mathrm{H}), 7.41-7.36(\mathrm{~m}, 4 \mathrm{H}), 7.15-7.11(\mathrm{~m}, 3 \mathrm{H}), 4.36-4.29(\mathrm{~m}, 2 \mathrm{H}), 3.15-3.09(\mathrm{~m}, 2 \mathrm{H})$, $1.34-1.30(\mathrm{~m}, 3 \mathrm{H})$. ESI-MS $(m / z)=370.06[\mathrm{M}+1]^{+}[29]$.

(S)-Ethyl 5-(2-amino-3-(3-fluorophenyl)propanamido)-1H-indole-2-carboxylatehydrochloride (14c): grey solid product $\left(3.7 \mathrm{~g}\right.$, $48.6 \%$ yield), m.p.: $154-156^{\circ} \mathrm{C}$, decomposition. ${ }^{1} \mathrm{H}-\mathrm{NMR}: \delta 11.86(\mathrm{~s}, 1 \mathrm{H}), 10.77(\mathrm{~s}, 1 \mathrm{H})$, $8.43(\mathrm{~s}, 3 \mathrm{H}), 7.95(\mathrm{~s}, 1 \mathrm{H}), 7.41-7.32(\mathrm{~m}, 3 \mathrm{H}), 7.22-7.05(\mathrm{~m}, 4 \mathrm{H}), 4.35-4.02(\mathrm{~m}, 3 \mathrm{H}), 3.37-3.11(\mathrm{~m}, 2 \mathrm{H})$, $1.35-1.31(\mathrm{t}, J=6.8 \mathrm{~Hz}, 3 \mathrm{H})$. ESI-MS $(\mathrm{m} / \mathrm{z})=370.02[\mathrm{M}+1]^{+}$, HRMS (ESI) calcd. For $\mathrm{C}_{20} \mathrm{H}_{21} \mathrm{FN}_{3} \mathrm{O}_{3}{ }^{+}$: $[\mathrm{M}+\mathrm{H}]^{+} m / z: 370.1561$, found: 370.1553 .

(S)-Ethyl 5-(2-amino-3-(pyridin-4-yl)propanamido)-1H-indole-2-carboxylatehydrochloride (14d): grey solid product $(0.5 \mathrm{~g}, 6.8 \%)$, m.p.: $171-173{ }^{\circ} \mathrm{C}$, decomposition. ${ }^{1} \mathrm{H}-\mathrm{NMR}: \delta 11.87(\mathrm{~s}, 1 \mathrm{H}), 11.32(\mathrm{~s}, 1 \mathrm{H}), 8.88-8.86$ $(\mathrm{d}, J=6.4 \mathrm{~Hz}, 2 \mathrm{H}), 8.59(\mathrm{~s}, 3 \mathrm{H}), 8.13-8.11(\mathrm{~d}, J=5.6 \mathrm{~Hz}, 2 \mathrm{H}), 8.03(\mathrm{~s}, 1 \mathrm{H}), 7.47-7.40(\mathrm{~m}, 2 \mathrm{H}), 7.12(\mathrm{~s}, 1 \mathrm{H})$, $4.57(\mathrm{~s}, 1 \mathrm{H}), 4.35-4.29(\mathrm{qd}, J=6.8 \mathrm{~Hz}$ and $7.2 \mathrm{~Hz}, 2 \mathrm{H}), 3.65-3.62(\mathrm{~m}, 1 \mathrm{H}), 3.41-3.35(\mathrm{~m}, 1 \mathrm{H}), 1.34-1.30$ $(\mathrm{t}, J=7.2 \mathrm{~Hz}, 3 \mathrm{H})$. ESI-MS $(m / z)=353.00[\mathrm{M}+1]^{+}$, HRMS (ESI) calcd. For $\mathrm{C}_{19} \mathrm{H}_{21} \mathrm{~N}_{4} \mathrm{O}_{3}{ }^{+}:[\mathrm{M}+\mathrm{H}]^{+}$ $m / z: 353.1608$, found: 353.1602 .

(S)-Ethyl 5-(2-amino-3-(pyridin-3-yl)propanamido)-1H-indole-2-carboxylatehydrochloride (14e): grey solid product $(1.5 \mathrm{~g}, 19.2 \%) .{ }^{1} \mathrm{H}-\mathrm{NMR}: \delta 11.90(\mathrm{~s}, 1 \mathrm{H}), 11.07(\mathrm{~s}, 1 \mathrm{H}), 8.89(\mathrm{~s}, 1 \mathrm{H}), 8.79-8.77(\mathrm{~d}, J=5.6 \mathrm{~Hz}$, $1 \mathrm{H}), 8.48-8.43(\mathrm{~m}, 4 \mathrm{H}), 8.00(\mathrm{~s}, 1 \mathrm{H}), 7.91-7.88(\mathrm{t}, J=6.4 \mathrm{~Hz}, 1 \mathrm{H}), 7.40(\mathrm{~s}, 1 \mathrm{H}), 7.13(\mathrm{~s}, 1 \mathrm{H}), 4.47(\mathrm{~s}, 1 \mathrm{H})$, 4.35-4.29 (m, 2H), 3.52-3.47 (m, 1H), 3.32-3.26 (m, 1H), 1.34-1.30 (m, 3H). ESI-MS $(m / z)=353.15[\mathrm{M}+1]^{+}$.

(S)-Ethyl 5-(2-amino-3-(pyridin-2-yl)propanamido)-1H-indole-2-carboxylatehydrochloride (14f): grey solid product $(1.8 \mathrm{~g}, 24.6 \%)$, m.p.: $75-77^{\circ} \mathrm{C}$, decomposition. ${ }^{1} \mathrm{H}-\mathrm{NMR}: \delta 11.86(\mathrm{~s}, 1 \mathrm{H}), 10.89(\mathrm{~s}, 1 \mathrm{H}), 8.76-8.75$ $(\mathrm{d}, J=5.2 \mathrm{~Hz}, 1 \mathrm{H}), 8.65(\mathrm{~s}, 3 \mathrm{H}), 8.21-8.19(\mathrm{~m}, 1 \mathrm{H}), 7.97(\mathrm{~s}, 1 \mathrm{H}), 7.81-7.79(\mathrm{~d}, J=7.6 \mathrm{~Hz}, 1 \mathrm{H}), 7.69-7.67$ (m, 1H), 7.42-7.38 (m, 2H), $7.11(\mathrm{~s}, 1 \mathrm{H}), 4.60(\mathrm{~s}, 1 \mathrm{H}), 4.35-4.29(\mathrm{~m}, 2 \mathrm{H}), 3.63-3.54(\mathrm{~m}, 2 \mathrm{H}), 1.34-1.30$ 
$(\mathrm{t}, J=7.2 \mathrm{~Hz}, 3 \mathrm{H})$. ESI-MS $(m / z)=353.05[\mathrm{M}+1]^{+}, \mathrm{HRMS}(\mathrm{ESI})$ calcd. For $\mathrm{C}_{19} \mathrm{H}_{21} \mathrm{~N}_{4} \mathrm{O}_{3}{ }^{+}:[\mathrm{M}+\mathrm{H}]^{+}$ $m / z: 353.1608$, found: 353.1604 .

(S)-Methyl 4-(2-(5-(3-chlorophenyl)-1H-pyrazole-3-carboxamido)-3-phenylpropanamido)benzoate (13a): To a mixture of 3-(3-chlorophenyl)-1H-pyrazole-5-carboxylic acid (14a, $133 \mathbf{m g}, 0.60 \mathbf{m m o l}) \mathrm{inDMF}(4 \mathrm{~mL})$ was added (S)-methyl-4-(2-amino-3-phenylpropanamido)benzoate hydrochloride (12, $200 \mathrm{mg}$, $0.60 \mathrm{mmol}), \mathrm{N}, \mathrm{N}$-diisopropyl-ethylamine $(232 \mathrm{mg}, 1.80 \mathrm{mmol})$, 1-hydroxybenzotriazole $(161 \mathrm{mg}$, $1.20 \mathrm{mmol}$ ) and $N$-(3-dimethylaminopropyl)- $N^{\prime}$-ethylcarbodiimide hydrochloride ( $229 \mathrm{mg}, 1.20 \mathrm{mmol}$ ) and the reaction mixture was stirred at room temperature overnight.Then TLC analysis indicated reaction was complete, and $\mathrm{H}_{2} \mathrm{O}(40 \mathrm{~mL})$ was added.The mixture was stirred for 10 min and filtered to get crude product 13a as a yellow solid, which was used for next step without further purification.

(S)-4-(2-(5-(3-Chlorophenyl)-1H-pyrazole-3-carboxamido)-3-phenylpropanamido)benzoic acid (7a): To a mixture of compound 13a (289 mg, $0.60 \mathrm{mmol})$ in $\mathrm{MeOH}(3 \mathrm{~mL})$ and $\mathrm{H}_{2} \mathrm{O}(1.5 \mathrm{~mL})$ was added $\mathrm{LiOH} \cdot \mathrm{H}_{2} \mathrm{O}(100 \mathrm{mg}$, $2.40 \mathrm{mmol}$ ) and the reaction mixture was stirred at $40{ }^{\circ} \mathrm{C}$ for $6 \mathrm{~h}$ when TLC analysis indicated completion of reaction. The mixture was evaporated in vacuum and $\mathrm{H}_{2} \mathrm{O}(2 \mathrm{~mL})$ was added, extracted by MTBE $(2 \mathrm{~mL})$ and acidified by hydrochloric acid $(1 \mathrm{M})$ to $\mathrm{pH} 3-4$. After stirred for $0.5 \mathrm{~h}$, the suspension was filtered, and the filter cake washed by $\mathrm{H}_{2} \mathrm{O}(5 \mathrm{~mL})$ and dried at $50{ }^{\circ} \mathrm{C}$ for $2 \mathrm{~h}$ to afford $7 \mathrm{a}$ as a white solid (185 mg, 63.4\% yield for 2 steps); m.p.: $147-149^{\circ} \mathrm{C}$, decomposition. ${ }^{1} \mathrm{H}-\mathrm{NMR}: \delta 13.68(\mathrm{~s}, 1 \mathrm{H}), 12.65$ (s, 1H), $10.57(\mathrm{~s}, 1 \mathrm{H}), 7.93-7.88(\mathrm{~m}, 3 \mathrm{H}), 7.73-7.71(\mathrm{~m}, 2 \mathrm{H}), 7.60-7.15(\mathrm{~m}, 8 \mathrm{H}), 4.93-4.88(\mathrm{~m}, 1 \mathrm{H}), 3.31-3.15$ (m, 2H) ${ }^{13}{ }^{1}$ C-NMR: $\delta$ 170.64, 167.03, 142.99, 137.61, 133.84, 130.88, 130.43, 129.34, 129.20, 128.20, 127.94, $126.51,125.55,124.88,123.91,118.78,103.51,55.29,37.46$. ESI-MS $(m / z)=488.90[\mathrm{M}+\mathrm{H}]^{+}$, HRMS (ESI) calcd. For $\mathrm{C}_{26} \mathrm{H}_{22} \mathrm{ClN}_{4} \mathrm{O}_{4}{ }^{+}:[\mathrm{M}+\mathrm{H}]^{+} m / z: 489.1324$, found: 489.1317 .

Compounds $\mathbf{7 b} \sim \mathbf{7 n}$ were synthesized according to the procedure described for the preparation of $\mathbf{7 a}$.

(S)-4-(3-Phenyl-2-(5-phenyl-1H-pyrazole-3-carboxamido)propanamido)benzoic acid (7b): white solid product (183 mg, 67.4\% yield), m.p.: 137-139 ${ }^{\circ} \mathrm{C}$, decomposition. ${ }^{1} \mathrm{H}-\mathrm{NMR}: \delta 13.68-13.64(\mathrm{~m}, 1 \mathrm{H}), 12.76-12.70$ $(\mathrm{m}, 1 \mathrm{H}), 10.52(\mathrm{~s}, 1 \mathrm{H}), 8.11-8.09(\mathrm{~m}, 1 \mathrm{H}), 7.91-7.88(\mathrm{~d}, J=8.4 \mathrm{~Hz}, 2 \mathrm{H}), 7.77-7.70(\mathrm{~m}, 4 \mathrm{H}), 7.46-7.43$ $(\mathrm{m}, 2 \mathrm{H}), 7.34-7.19(\mathrm{~m}, 5 \mathrm{H}), 7.17-7.09(\mathrm{~m}, 1 \mathrm{H}), 7.06(\mathrm{~s}, 1 \mathrm{H}), 4.93-4.87(\mathrm{~m}, 1 \mathrm{H}), 3.16-3.15(\mathrm{~m}, 2 \mathrm{H})$. ${ }^{13}$ C-NMR: $\delta 171.25,167.67,161.28,143.49,138.15,131.10,129.92,129.82,129.62,128.84,127.16,126.24$, $125.92,119.42,103.42,55.67,38.12$. ESI-MS $(m / z)=454.99[\mathrm{M}+\mathrm{H}]^{+}$, HRMS (ESI) calcd. For $\mathrm{C}_{26} \mathrm{H}_{23} \mathrm{~N}_{4} \mathrm{O}_{4}{ }^{+}:[\mathrm{M}+\mathrm{H}]^{+} m / z: 455.1714$, found: 455.1703 .

(S)-4-(2-(5-(2-Fluorophenyl)-1H-pyrazole-3-carboxamido)-3-phenylpropanamido)benzoic acid (7c): white solid product $\left(220 \mathrm{mg}, 77.9 \%\right.$ yield), m.p.: $86-88{ }^{\circ} \mathrm{C}$, decomposition. ${ }^{1} \mathrm{H}-\mathrm{NMR}: \delta 13.76-13.69(\mathrm{~m}, 1 \mathrm{H})$, $12.79-12.68(\mathrm{~m}, 1 \mathrm{H}), 10.57(\mathrm{~s}, 1 \mathrm{H}), 9.02-8.97(\mathrm{~m}, 1 \mathrm{H}), 7.90-7.88(\mathrm{~d}, J=8.8 \mathrm{~Hz}, 2 \mathrm{H}), 7.73-7.71(\mathrm{~d}, J=8.4 \mathrm{~Hz}$, 2H), 7.39-7.17 (m, 8H), 7.15-7.07 (m, 1H), $7.00(\mathrm{~s}, 1 \mathrm{H}), 4.93-4.87(\mathrm{~m}, 1 \mathrm{H}), 3.23-3.15(\mathrm{~m}, 2 \mathrm{H})$. ESI-MS $(m / z)=472.99[\mathrm{M}+\mathrm{H}]^{+} .{ }^{13} \mathrm{C}-\mathrm{NMR}: \delta 171.38,167.65,160.65,143.73,138.34,130.98,130.70,130.01,129.79$, $128.75,127.08,126.09,125.49,119.39,116.81,106.49,56.03,37.90$. HRMS (ESI) calcd. For $\mathrm{C}_{26} \mathrm{H}_{22} \mathrm{FN}_{4} \mathrm{O}_{4}{ }^{+}$: $[\mathrm{M}+\mathrm{H}]^{+} m / z: 473.1620$, found: 473.1600 .

(S)-4-(2-(5-(2-Chlorophenyl)-1H-pyrazole-3-carboxamido)-3-phenylpropanamido)benzoic acid (7d): white solid product $\left(221 \mathrm{mg}, 75.7 \%\right.$ yield), m.p.: $92-94{ }^{\circ} \mathrm{C}$, decomposition. ${ }^{1} \mathrm{H}-\mathrm{NMR}: \delta 13.31(\mathrm{~s}, 1 \mathrm{H}), 10.95(\mathrm{~s}, 1 \mathrm{H})$, $8.68(\mathrm{~s}, 1 \mathrm{H}), 7.94-7.92(\mathrm{~d}, J=8.8 \mathrm{~Hz}, 2 \mathrm{H}), 7.84-7.82(\mathrm{~d}, J=8.4 \mathrm{~Hz}, 2 \mathrm{H}), 7.74-7.72(\mathrm{~d}, J=6.8 \mathrm{~Hz}, 1 \mathrm{H})$, $7.55-7.53(\mathrm{~d}, J=7.2 \mathrm{~Hz}, 1 \mathrm{H}), 7.42-7.35(\mathrm{~m}, 4 \mathrm{H}), 7.31-7.22(\mathrm{~m}, 3 \mathrm{H}), 7.17-7.14(\mathrm{~m}, 1 \mathrm{H}), 5.01-4.95(\mathrm{~m}, 1 \mathrm{H})$, 3.28-3.11 (m, 2H). ${ }^{13} \mathrm{C}-\mathrm{NMR}: \delta$ 172.94, 170.79, 167.03, 143.12, 137.74, 131.15, 130.57, 129.94, 129.40, 129.19, 128.30, 127.53, 126.54, 125.47, 118.82, 106.57, 55.39, 36.41. ESI-MS $(m / z)=489.01[\mathrm{M}+\mathrm{H}]^{+}$, HRMS (ESI) calcd. For $\mathrm{C}_{26} \mathrm{H}_{22} \mathrm{ClN}_{4} \mathrm{O}_{4}{ }^{+}:[\mathrm{M}+\mathrm{H}]^{+} m / z: 489.1324$, found: 489.1309 .

(S)-4-(2-(5-(4-Chlorophenyl)-1H-pyrazole-3-carboxamido)-3-phenylpropanamido)benzoic acid (7e): white solid product (177 mg, 60.3\% yield), m.p.: $174-176{ }^{\circ} \mathrm{C}$, decomposition. ${ }^{1} \mathrm{H}-\mathrm{NMR}: \delta 13.74-13.63(\mathrm{~m}, 1 \mathrm{H})$, $12.66(\mathrm{~s}, 1 \mathrm{H}), 10.49(\mathrm{~s}, 1 \mathrm{H}), 10.37(\mathrm{~s}, 1 \mathrm{H}), 7.91-7.86(\mathrm{t}, J=8.8 \mathrm{~Hz}, 2 \mathrm{H}), 7.80-7.78(\mathrm{~d}, J=8.0 \mathrm{~Hz}, 1 \mathrm{H})$, 7.72-7.67 (m, 2H), 7.51 (s, 2H), 7.27-7.15 (m, 6H), $7.08(\mathrm{~s}, 1 \mathrm{H}), 4.90-4.89(\mathrm{~m}, 1 \mathrm{H}), 3.17-3.15(\mathrm{~m}, 2 \mathrm{H})$. 
${ }^{13}$ C-NMR: $\delta$ 170.59, 168.12, 160.16, 142.37, 137.66, 132.74, 130.36, 129.35, 129.02, 128.23, 127.97, 127.58, $127.04,126.54,118.72,103.22,55.37,37.50$. ESI-MS $(m / z)=488.89[\mathrm{M}+\mathrm{H}]^{+}$, HRMS (ESI) calcd. For $\mathrm{C}_{26} \mathrm{H}_{22} \mathrm{ClN}_{4} \mathrm{O}_{4}{ }^{+}:[\mathrm{M}+\mathrm{H}]^{+} m / z: 489.1324$, found: 489.1311 .

(S)-4-(2-(5-(3-Chloro-2-fluorophenyl)-1H-pyrazole-3-carboxamido)-3-phenylpropanamido)benzoic acid (7f): white solid product $\left(258 \mathrm{mg}, 84.8 \%\right.$ yield), m.p.: $185-187^{\circ} \mathrm{C}$, decomposition. ${ }^{1} \mathrm{H}-\mathrm{NMR}: \delta 13.86(\mathrm{~s}, 1 \mathrm{H}$,), $12.69(\mathrm{~s}, 1 \mathrm{H}), 10.54(\mathrm{~s}, 1 \mathrm{H}), 10.38(\mathrm{~s}, 1 \mathrm{H}), 8.31-8.29(\mathrm{~d}, J=8.0 \mathrm{~Hz}, 1 \mathrm{H}), 7.91-7.86(\mathrm{~m}, 2 \mathrm{H}), 7.73-7.67$ $(\mathrm{m}, 2 \mathrm{H}), 7.57(\mathrm{~s}, 1 \mathrm{H}), 7.35-7.19(\mathrm{~m}, 5 \mathrm{H}), 7.17-7.15(\mathrm{~m}, 1 \mathrm{H}), 4.91-4.89(\mathrm{~m}, 1 \mathrm{H}), 3.16-2.99(\mathrm{~m}, 1 \mathrm{H}), 2.86-2.81$ (m, 1H). ${ }^{13}$ C-NMR: $\delta$ 170.70, 168.35, 159.87, 155.44, 142.28, 137.77, 130.47, 129.42, 128.36, 128.00, 127.03, $126.68,125.87,121.01,118.85,106.21,55.55,37.46$. ESI-MS $(m / z)=506.93[\mathrm{M}+\mathrm{H}]^{+}$, HRMS (ESI) calcd. For $\mathrm{C}_{26} \mathrm{H}_{21} \mathrm{ClFN}_{4} \mathrm{O}_{4}{ }^{+}:[\mathrm{M}+\mathrm{H}]^{+} m / z: 507.1230$, found: 507.1220.

(S)-4-(2-(5-(4-Chloro-2-fluorophenyl)-1H-pyrazole-3-carboxamido)-3-phenylpropanamido)benzoic acid (7g): white solid product $\left(220 \mathrm{mg}, 72.6 \%\right.$ yield), m.p.: $143-145{ }^{\circ} \mathrm{C}$, decomposition. ${ }^{1} \mathrm{H}-\mathrm{NMR}: \delta 13.82$ $(\mathrm{s}, 1 \mathrm{H}), 12.70(\mathrm{~s}, 1 \mathrm{H}), 10.55(\mathrm{~s}, 1 \mathrm{H}), 9.00(\mathrm{~s}, 1 \mathrm{H}), 7.94(\mathrm{~s}, 1 \mathrm{H}), 7.90-7.88(\mathrm{~d}, J=8.4 \mathrm{~Hz}, 2 \mathrm{H}), 7.73-7.71$ $(\mathrm{d}, J=8.4 \mathrm{~Hz}, 2 \mathrm{H}), 7.58-7.56(\mathrm{~m}, 1 \mathrm{H}), 7.35-7.27(\mathrm{~m}, 3 \mathrm{H}), 7.26-7.24(\mathrm{~m}, 2 \mathrm{H}), 7.18-7.15(\mathrm{~m}, 1 \mathrm{H}), 4.93-4.87$ (m, 1H), 3.18-3.11 (m, 2H). ${ }^{13} \mathrm{C}-\mathrm{NMR}: \delta 171.27,167.62,160.54,158.03,143.55,138.26,133.94,131.04$, $129.91,128.78,127.11,126.15,125.80,119.39,117.65,106.48,55.92,37.90$. HRMS (ESI) calcd. For $\mathrm{C}_{26} \mathrm{H}_{21} \mathrm{ClFN}_{4} \mathrm{O}_{4}{ }^{+}:[\mathrm{M}+\mathrm{H}]^{+} m / z: 507.1230$, found: 507.1215.

(S)-4-(2-(5-(5-Chloro-2-fluorophenyl)-1H-pyrazole-3-carboxamido)-3-phenylpropanamido)benzoic acid (7h): grey solid product $\left(176 \mathrm{mg}, 57.9 \%\right.$ yield), m.p.: $179-181^{\circ} \mathrm{C}$, decomposition. ${ }^{1} \mathrm{H}-\mathrm{NMR}: \delta 13.89-13.83$ $(\mathrm{m}, 1 \mathrm{H}), 12.78(\mathrm{~s}, 1 \mathrm{H}), 10.55(\mathrm{~s}, 1 \mathrm{H}), 8.78-8.77(\mathrm{~m}, 1 \mathrm{H}), 7.96-7.94(\mathrm{~m}, 1 \mathrm{H}), 7.90-7.88(\mathrm{~d}, J=8.8 \mathrm{~Hz}$, $2 \mathrm{H}), 7.71-7.69(\mathrm{~d}, J=8.4 \mathrm{~Hz}, 2 \mathrm{H}), 7.47-7.18(\mathrm{~m}, 6 \mathrm{H}), 7.16-7.15(\mathrm{~m}, 1 \mathrm{H}), 4.92-4.87(\mathrm{~m}, 1 \mathrm{H}), 3.19-3.07$ (m, 2H). $\left.{ }^{13} \mathrm{C}-\mathrm{NMR}\right): \delta 171.21,168.05,159.40,143.20,138.31,130.98,129.88,129.5,128.80,127.73,127.11$, $119.32,119.13,118.89,106.79,55.95,37.90$. ESI-MS $(m / z)=506.87[\mathrm{M}+\mathrm{H}]^{+}$, HRMS (ESI) calcd. For $\mathrm{C}_{26} \mathrm{H}_{21} \mathrm{ClFN}_{4} \mathrm{O}_{4}{ }^{+}:[\mathrm{M}+\mathrm{H}]^{+} m / z: 507.1230$, found: 507.1221.

(S)-4-(2-(5-(2-Chloro-6-fluorophenyl)-1H-pyrazole-3-carboxamido)-3-phenylpropanamido)benzoic acid (7i): white solid product $\left(189 \mathrm{mg}, 62.1 \%\right.$ yield), m.p.: $203-205^{\circ} \mathrm{C}$, decomposition. ${ }^{1} \mathrm{H}-\mathrm{NMR}: \delta 13.74-13.70$ $(\mathrm{m}, 1 \mathrm{H}), 10.64(\mathrm{~s}, 1 \mathrm{H}), 7.89-7.87(\mathrm{~d}, J=8.8 \mathrm{~Hz}, 2 \mathrm{H}), 7.71-7.69(\mathrm{~d}, J=8.4 \mathrm{~Hz}, 2 \mathrm{H}), 7.54-7.42(\mathrm{~m}, 2 \mathrm{H})$, 7.38-7.36 (m, 3H), 7.28-7.24 (m, 2H), 7.19-7.15 (m, 1H), 7.08-6.98 (m, 1H), 4.92-4.86 (m, 1H), 3.21-3.09 (m, 2H). ${ }^{13} \mathrm{C}-\mathrm{NMR}: \delta 171.31,168.49,162.00,143.11,138.33,134.48,130.98,129.94,128.82,127.69,127.14$, 126.53, 119.26, 115.63, 115.40, 108.35, 56.03, 37.88. ESI-MS $(m / z)=506.88[\mathrm{M}+\mathrm{H}]^{+}$, HRMS (ESI) calcd. For $\mathrm{C}_{26} \mathrm{H}_{21} \mathrm{ClFN}_{4} \mathrm{O}_{4}{ }^{+}:[\mathrm{M}+\mathrm{H}]^{+} m / z: 507.1230$, found: 507.1213.

(S)-4-(2-(5-(2,6-Difluorophenyl)-1H-pyrazole-3-carboxamido)-3-phenylpropanamido)benzoic acid (7j): white solid product (153 mg, 50.6\% yield), m.p.: $205-207{ }^{\circ} \mathrm{C}$, decomposition. ${ }^{1} \mathrm{H}-\mathrm{NMR}: \delta 13.66(\mathrm{~s}, 1 \mathrm{H})$, $12.79-12.70(\mathrm{~m}, 1 \mathrm{H}), 10.54(\mathrm{~s}, 1 \mathrm{H}), 7.91-7.89(\mathrm{~d}, J=8.4 \mathrm{~Hz}, 2 \mathrm{H}), 7.73-7.70(\mathrm{~d}, J=8.4 \mathrm{~Hz}, 2 \mathrm{H}), 7.50(\mathrm{~s}, 1 \mathrm{H})$, 7.35-7.03 (m, 6H), 7.03-6.99 (m, 2H), 4.91-4.89 (m, 1H), 3.16-3.15 (m, 2H). ${ }^{13} \mathrm{C}-\mathrm{NMR}: \delta 170.65,166.99$, 160.63, 160.18, 158.08, 142.90, 137.62, 130.76, 130.46, 129.27, 128.20, 126.51, 125.53, 118.77, 112.31, 107.44, 55.16, 37.34. ESI-MS $(m / z)=490.98[\mathrm{M}+\mathrm{H}]^{+}$, HRMS (ESI) calcd. For $\mathrm{C}_{26} \mathrm{H}_{21} \mathrm{~F}_{2} \mathrm{~N}_{4} \mathrm{O}_{4}{ }^{+}:[\mathrm{M}+\mathrm{H}]^{+} m / z$ : 491.1525, found: 491.1500 .

(S)-4-(2-(5-(3-Chloro-2,6-difluorophenyl)-1H-pyrazole-3-carboxamido)-3-phenylpropanamido)benzoicacid (7k): white solid product (220 mg, 70.2\% yield), m.p.: $129-131^{\circ} \mathrm{C}$, decomposition. ${ }^{1} \mathrm{H}-\mathrm{NMR}: \delta 13.80(\mathrm{~s}, 1 \mathrm{H})$, $12.74(\mathrm{~s}, 1 \mathrm{H}), 10.53(\mathrm{~s}, 1 \mathrm{H}), 7.91-7.89(\mathrm{~d}, J=8.4 \mathrm{~Hz}, 2 \mathrm{H}), 7.73-7.70(\mathrm{~m}, 3 \mathrm{H}), 7.34-7.04(\mathrm{~m}, 8 \mathrm{H}), 4.93-4.87$ (m, 1H), 3.18-3.15 (m, 2H). ${ }^{13} \mathrm{C}-\mathrm{NMR}: \delta 171.23,167.60,157.27,143.45,138.22,131.08,129.86,128.81$, $127.13,126.20,119.39,117.07,113.99,113.77,108.30,55.82,37.94$. ESI-MS $(m / z)=525.00[\mathrm{M}+\mathrm{H}]^{+}$, HRMS (ESI) calcd. For $\mathrm{C}_{26} \mathrm{H}_{20} \mathrm{ClF}_{2} \mathrm{~N}_{4} \mathrm{O}_{4}{ }^{+}:[\mathrm{M}+\mathrm{H}]^{+} m / z: 525.1136$, found: 525.1116.

(S)-4-(2-(5-(4-Chloro-2,6-difluorophenyl)-1H-pyrazole-3-carboxamido)-3-phenylpropanamido)benzoic acid (71): white solid product $\left(220 \mathrm{mg}\right.$, $70.2 \%$ yield), m.p.: $123-125{ }^{\circ} \mathrm{C}$, decomposition. ${ }^{1} \mathrm{H}-\mathrm{NMR}: \delta 13.93-13.77$ $(\mathrm{m}, 1 \mathrm{H}), 12.78-12.72(\mathrm{~m}, 1 \mathrm{H}), 10.59(\mathrm{~s}, 1 \mathrm{H}), 9.04-9.02(\mathrm{~m}, 1 \mathrm{H}), 7.91-7.89(\mathrm{~d}, J=8.8 \mathrm{~Hz}, 2 \mathrm{H}), 7.73-7.71$ 
$(\mathrm{d}, J=8.8 \mathrm{~Hz}, 2 \mathrm{H}), 7.54(\mathrm{~s}, 2 \mathrm{H}), 7.36-7.34(\mathrm{~m}, 2 \mathrm{H}), 7.27-7.24(\mathrm{~m}, 2 \mathrm{H}), 7.18-7.10(\mathrm{~m}, 1 \mathrm{H}), 6.99-6.96$ (m, 1H), 4.91-4.86 (m, 1H), 3.17-3.14 (m, 2H). ${ }^{13} \mathrm{C}-\mathrm{NMR}: \delta 171.30,167.68,158.58,143.52,138.27,131.07$, 129.91, 128.80, 127.13, 126.19, 119.34, 114.11, 113.83, 108.14, 55.92, 37.86. ESI-MS $(m / z)=525.01$ $[\mathrm{M}+\mathrm{H}]^{+}$, HRMS (ESI) calcd. For $\mathrm{C}_{26} \mathrm{H}_{20} \mathrm{ClF}_{2} \mathrm{~N}_{4} \mathrm{O}_{4}{ }^{+}:[\mathrm{M}+\mathrm{H}]^{+} m / z: 525.1136$, found: 525.1126.

(S)-4-(2-(5-(3-Chlorophenyl)-4-methyl-1H-pyrazole-3-carboxamido)-3-phenylpropanamido)benzoic acid (7m): white solid product $\left(29 \mathrm{mg}, 9.8 \%\right.$ yield), m.p.: $164-166{ }^{\circ} \mathrm{C}$, decomposition. ${ }^{1} \mathrm{H}-\mathrm{NMR}: \delta 13.48(\mathrm{~s}, 1 \mathrm{H}), 12.70$ $(\mathrm{s}, 1 \mathrm{H}), 10.48(\mathrm{~s}, 1 \mathrm{H}), 8.01-7.98(\mathrm{~m}, 1 \mathrm{H}), 7.91-7.89(\mathrm{~m}, 2 \mathrm{H}), 7.71-7.69(\mathrm{~m}, 2 \mathrm{H}), 7.60(\mathrm{~s}, 1 \mathrm{H}), 7.54-7.49(\mathrm{~m}, 3 \mathrm{H})$, 7.29-7.21 (m, 4H), 7.21-7.19 (m, 1H), 4.90-4.88 (m, 1H), 3.17-3.15 (m, 2H), $2.29(\mathrm{~s}, 3 \mathrm{H})$. ESI-MS $(\mathrm{m} / \mathrm{z})=$ $503.00[\mathrm{M}+\mathrm{H}]^{+}$, HRMS (ESI) calcd. For $\mathrm{C}_{27} \mathrm{H}_{24} \mathrm{ClN}_{4} \mathrm{O}_{4}{ }^{+}:[\mathrm{M}+\mathrm{H}]^{+} m / z: 503.1481$, found: 503.1467.

(S)-4-(2-(5-(3-Chlorophenyl)-4-ethyl-1H-pyrazole-3-carboxamido)-3-phenylpropanamido)benzoic acid (7n): white solid product $\left(227 \mathrm{mg}, 73.5 \%\right.$ yield), m.p.: $126-128{ }^{\circ} \mathrm{C}$, decomposition. ${ }^{1} \mathrm{H}-\mathrm{NMR}: \delta 13.46$ $(\mathrm{s}, 1 \mathrm{H}), 12.74(\mathrm{~s}, 1 \mathrm{H}), 10.54(\mathrm{~s}, 1 \mathrm{H}), 8.01(\mathrm{~s}, 1 \mathrm{H}), 7.91-7.89(\mathrm{~d}, J=8.4 \mathrm{~Hz}, 2 \mathrm{H}), 7.72-7.70(\mathrm{~d}, J=8.8 \mathrm{~Hz}$, $2 \mathrm{H}), 7.54-7.45(\mathrm{~m}, 4 \mathrm{H}), 7.31-7.24(\mathrm{~m}, 4 \mathrm{H}), 7.20-7.16(\mathrm{~m}, 1 \mathrm{H}), 4.93-4.88(\mathrm{qd}, J=8.0 \mathrm{~Hz}, 1 \mathrm{H}), 3.21-3.10$ $(\mathrm{m}, 2 \mathrm{H}), 2.75-2.69(\mathrm{qd}, J=7.2 \mathrm{~Hz}, 2 \mathrm{H}), 1.04-1.01(\mathrm{~m}, 3 \mathrm{H})$. ESI-MS $(\mathrm{m} / \mathrm{z})=516.91[\mathrm{M}+\mathrm{H}]^{+}$, HRMS (ESI) calcd. For $\mathrm{C}_{28} \mathrm{H}_{26} \mathrm{ClN}_{4} \mathrm{O}_{4}{ }^{+}:[\mathrm{M}+\mathrm{H}]^{+} m / z: 517.1637$, found: 517.1624.

(S)-Ethyl 5-(2-(3-(3-chloro-2-fluorophenyl)-1H-pyrazole-5-carboxamido)-3-phenylpropanamido)-1H-indole-2carboxylate (15o): To a mixture of 3-(3-chloro-2-fluorophenyl)-1H-pyrazole-5-carboxylic acid (11f, $136 \mathrm{mg}, 0.57 \mathrm{mmol})$ in DMF (3 mL) was added 1-hydroxybenzotriazole (139 mg, $1.04 \mathrm{mmol})$, (S)-ethyl 5-(2-amino-3-phenylpropanamido)-1H-indole-2-carboxylate hydrochloride (14a, $200 \mathrm{mg}$, $0.52 \mathrm{mmol}$ ), $N$-(3-dimethylaminopropyl)- $N^{\prime}$-ethylcarbodiimide hydrochloride (198 $\mathrm{mg}, 1.04 \mathrm{mmol}$ ) and $N, N$-diisopropylethylamine $(200 \mathrm{mg}, 1.56 \mathrm{mmol})$, then the reaction mixture was stirred at room temperature overnight.TLC analysis indicated reaction was complete and $\mathrm{H}_{2} \mathrm{O}(30 \mathrm{~mL})$ was added. The suspension was stirred for $0.5 \mathrm{~h}$ and filtered.The filter cake was washed by $\mathrm{H}_{2} \mathrm{O}(5 \mathrm{~mL})$ to get crude product $15 \mathrm{o}$ (130 mg, 44.2\% yield) as a brown solid, which was used for next step without further purification.

(S)-5-(2-(3-(3-Chloro-2-fluorophenyl)-1H-pyrazole-5-carboxamido)-3-phenylpropanamido)-1H-indole-2-

carboxylic acid (7o): To a suspension of compound $150(130 \mathrm{mg}, 0.23 \mathrm{mmol})$ in EtOH $(3 \mathrm{~mL})$ and $\mathrm{H}_{2} \mathrm{O}$ $(1.5 \mathrm{~mL})$ was added $\mathrm{LiOH} \cdot \mathrm{H}_{2} \mathrm{O}(38 \mathrm{mg}, 0.92 \mathrm{mmol})$ and the reaction mixture was stirred at $40{ }^{\circ} \mathrm{C}$ for $6 \mathrm{~h}$ when TLC analysis indicated completion of reaction. The reaction mixture was evaporated on a rotary evaporator in vacuum and $\mathrm{H}_{2} \mathrm{O}(4 \mathrm{~mL})$ was added. The solution was extracted by MTBE $(2 \mathrm{~mL})$, acidified by hydrochloric acid $(1 \mathrm{M})$ to $\mathrm{pH} 3-4$. After stirred for $0.5 \mathrm{~h}$, the suspension was filtered, washed by $\mathrm{H}_{2} \mathrm{O}(5 \mathrm{~mL})$ and the filter cake was dried at $50{ }^{\circ} \mathrm{C}$ for $2 \mathrm{~h}$ to afford $7 \mathbf{o}$ as a white solid (112 mg, 39.6\% yield for 2 steps), m.p.: $172-174{ }^{\circ} \mathrm{C}$, decomposition. ${ }^{1} \mathrm{H}-\mathrm{NMR}: \delta 13.84(\mathrm{~s}, 1 \mathrm{H}), 12.81$ $(\mathrm{s}, 1 \mathrm{H}), 11.67(\mathrm{~s}, 1 \mathrm{H}), 10.11(\mathrm{~s}, 1 \mathrm{H}), 7.98(\mathrm{~s}, 1 \mathrm{H}), 7.88(\mathrm{~s}, 1 \mathrm{H}), 7.58(\mathrm{~s}, 1 \mathrm{H}), 7.52-7.11(\mathrm{~m}, 11 \mathrm{H}), 7.04(\mathrm{~s}, 1 \mathrm{H})$, 4.93-4.87 (m, 1H), 3.20-3.10 (m, 2H). HRMS (ESI) calcd. for $\mathrm{C}_{28} \mathrm{H}_{22} \mathrm{ClFN}_{5} \mathrm{O}_{4}{ }^{+}:[\mathrm{M}+\mathrm{H}]^{+} m / z: 546.1339$, found: 546.1325 .

Compounds $\mathbf{7 p} \sim \mathbf{7 w}$ were synthesized according to the procedure described for the preparation of $\mathbf{7 0}$.

(S)-5-(2-(3-(3-Chloro-2,6-difluorophenyl)-1H-pyrazole-5-carboxamido)-3-phenylpropanamido)-1H-indole-2carboxylic acid $(7 \mathrm{p})$ : white solid product $\left(91 \mathrm{mg}, 31.2 \%\right.$ yield), m.p.: $164-166{ }^{\circ} \mathrm{C}$, decomposition. ${ }^{1} \mathrm{H}-\mathrm{NMR}: \delta 13.96(\mathrm{~s}, 1 \mathrm{H}), 12.98(\mathrm{~s}, 1 \mathrm{H}), 11.61(\mathrm{~s}, 1 \mathrm{H}), 10.30(\mathrm{~s}, 1 \mathrm{H}), 8.93(\mathrm{~s}, 1 \mathrm{H}), 7.96(\mathrm{~s}, 1 \mathrm{H}), 7.85(\mathrm{~s}, 1 \mathrm{H})$, 7.71-7.17 (m, 9H), $6.99(\mathrm{~s}, 1 \mathrm{H}), 4.90-4.89(\mathrm{~m}, 1 \mathrm{H}), 3.20-3.16(\mathrm{~m}, 2 \mathrm{H})$. ESI-MS $(\mathrm{m} / z)=563.87[\mathrm{M}+\mathrm{H}]^{+}$, HRMS (ESI) calcd. For $\mathrm{C}_{28} \mathrm{H}_{21} \mathrm{ClF}_{2} \mathrm{~N}_{5} \mathrm{O}_{4}{ }^{+}:[\mathrm{M}+\mathrm{H}]^{+} m / z: 564.1245$, found: 564.1234.

(S)-5-(2-(3-(3-Cchlorophenyl)-4-methyl-1H-pyrazole-5-carboxamido)-3-phenylpropanamido)-1H-indole-2carboxylic acid (7q): white solid product $\left(60 \mathrm{mg}, 21.5 \%\right.$ yield), m.p.: $154-156{ }^{\circ} \mathrm{C}$, decomposition. ${ }^{1} \mathrm{H}-\mathrm{NMR}: \delta 13.48(\mathrm{~s}, 1 \mathrm{H}), 11.66(\mathrm{~s}, 1 \mathrm{H}), 10.06(\mathrm{~s}, 1 \mathrm{H}), 7.98(\mathrm{~s}, 1 \mathrm{H}), 7.96-7.91(\mathrm{~m}, 1 \mathrm{H}), 7.60(\mathrm{~s}, 1 \mathrm{H}), 7.52$ (s, 1H), 7.38-7.14 (m, 9H), 7.03 (s, 1H), 4.93-4.87 (m, 1H), 3.19-3.16 (m, 2H), $2.31(\mathrm{~s}, 3 \mathrm{H})$. ESI-MS $(\mathrm{m} / \mathrm{z})$ $=541.99[\mathrm{M}+\mathrm{H}]^{+}, \mathrm{HRMS}$ (ESI) calcd. For $\mathrm{C}_{29} \mathrm{H}_{25} \mathrm{ClN}_{5} \mathrm{O}_{4}{ }^{+}:[\mathrm{M}+\mathrm{H}]^{+} m / z: 542.1590$, found: 542.1577 . 
(S)-5-(2-(3-(3-Chlorophenyl)-1,4-dimethyl-1H-pyrazole-5-carboxamido)-3-phenylpropanamido)-1H-indole2-carboxylic acid (7r): white solid product (59 mg, 20.9\% yield), m.p.: $148-150{ }^{\circ} \mathrm{C}$, decomposition. ${ }^{1} \mathrm{H}-\mathrm{NMR}: \delta 12.86(\mathrm{~s}, 1 \mathrm{H}), 11.66(\mathrm{~s}, 1 \mathrm{H}), 10.05$ (s, 1H), $7.94(\mathrm{~s}, 1 \mathrm{H}), 7.85-7.83$ (d, J = 8.4 Hz, 1H), 7.56-7.53 $(\mathrm{m}, 3 \mathrm{H}), 7.40-7.24(\mathrm{~m}, 6 \mathrm{H}), 7.20-7.18(\mathrm{~m}, 1 \mathrm{H}), 7.03(\mathrm{~s}, 1 \mathrm{H}), 4.94-4.89(\mathrm{~m}, 1 \mathrm{H}), 3.75(\mathrm{~s}, 3 \mathrm{H}), 3.18-3.10$ $(\mathrm{m}, 2 \mathrm{H}), 2.09$ (s, 3H). HRMS (ESI) calcd. For $\mathrm{C}_{30} \mathrm{H}_{27} \mathrm{ClN}_{5} \mathrm{O}_{4}{ }^{+}:[\mathrm{M}+\mathrm{H}]^{+} \mathrm{m} / z:$ 556.1746, found: 556.1735.

(S)-5-(2-(3-(3-Chloro-2-fluorophenyl)-1H-pyrazole-5-carboxamido)-3-(4-fluorophenyl)propanamido)-1H-indole -2-carboxylic acid (7s): white solid product (151 mg, 54.3\% yield), m.p.: $186-188{ }^{\circ} \mathrm{C}$, decomposition. ${ }^{1} \mathrm{H}-\mathrm{NMR}: \delta 13.87(\mathrm{~s}, 1 \mathrm{H}), 12.99-12.88(\mathrm{~m}, 1 \mathrm{H}), 11.64(\mathrm{~s}, 1 \mathrm{H}), 10.15(\mathrm{~s}, 1 \mathrm{H}), 8.99-8.91(\mathrm{~m}, 1 \mathrm{H}), 7.97(\mathrm{~s}, 1 \mathrm{H})$, $7.94(\mathrm{~s}, 1 \mathrm{H}), 7.58(\mathrm{~s}, 1 \mathrm{H}), 7.39-7.29(\mathrm{~m}, 5 \mathrm{H}), 7.15-7.02(\mathrm{~m}, 2 \mathrm{H}), 6.96(\mathrm{~s}, 1 \mathrm{H}), 4.90-4.85(\mathrm{~m}, 1 \mathrm{H}), 3.30-3.09$ (m, 2H). ${ }^{13} \mathrm{C}-\mathrm{NMR}: \delta 169.64,163.18,162.37,159.96,155.40,152.91,134.32,134.16,131.74,131.32,131.24$, 130.08, 129.90, 126.99, 126.91, 125.79, 120.96, 118.76, 115.04, 114.83, 112.63, 112.26, 107.16, 106.21, 55.32, 36.93. ESI-MS $(m / z)=563.82[\mathrm{M}+\mathrm{H}]^{+}$, HRMS (ESI) calcd. For $\mathrm{C}_{28} \mathrm{H}_{21} \mathrm{ClF}_{2} \mathrm{~N}_{5} \mathrm{O}_{4}{ }^{+}:[\mathrm{M}+\mathrm{H}]^{+} m / z$ : 564.1245, found: 564.1234 .

(S)-5-(2-(3-(3-Chloro-2-fluorophenyl)-1H-pyrazole-5-carboxamido)-3-(3-fluorophenyl)propanamido)-1H-indole2-carboxylic acid (7t): white solid product $\left(154 \mathrm{mg}, 55.7 \%\right.$ yield), m.p.: $174-176{ }^{\circ} \mathrm{C}$, decomposition. ${ }^{1} \mathrm{H}-\mathrm{NMR}$ : $\delta$ 13.92-13.75 (m, 1H), 13.03-12.81 (m, 1H), $11.66(\mathrm{~s}, 1 \mathrm{H}), 10.12(\mathrm{~s}, 1 \mathrm{H}), 7.97$ (s, $\left.1 \mathrm{H}\right), 7.87$ (s, 1H), 7.59-7.56 (m, 1H), 7.54-7.27 (m, 5H), 7.21-6.93 (m, 4H), 4.94-4.88 (m, 1H), 3.29-3.13 (m, 2H). ESI-MS $(m / z)=563.84[\mathrm{M}+\mathrm{H}]^{+}, \mathrm{HRMS}(\mathrm{ESI})$ calcd. For $\mathrm{C}_{28} \mathrm{H}_{21} \mathrm{ClF}_{2} \mathrm{~N}_{5} \mathrm{O}_{4}{ }^{+}:[\mathrm{M}+\mathrm{H}]^{+} m / z: 564.1245$, found: 564.1234 .

(S)-5-(2-(3-(3-Chloro-2-fluorophenyl)-1H-pyrazole-5-carboxamido)-3-(pyridin-4-yl)propanamido)-1H-indole2-carboxylic acid (7u): grey solid product $\left(92 \mathrm{mg}, 32.7 \%\right.$ yield), m.p.: $199-201{ }^{\circ} \mathrm{C}$, decomposition. ${ }^{1} \mathrm{H}-\mathrm{NMR}$ : $\delta 13.87$ (s, 1H), 12.83 (s, 1H), 11.69 (s, 1H), $8.96(\mathrm{~s}, 1 \mathrm{H}), 8.50(\mathrm{~s}, 1 \mathrm{H}), 7.98(\mathrm{~s}, 1 \mathrm{H}), 7.93(\mathrm{~s}, 1 \mathrm{H})$, 7.69-7.39 (m, 6H), $7.05(\mathrm{~s}, 1 \mathrm{H}), 5.00-4.95(\mathrm{~m}, 1 \mathrm{H}), 3.27-3.17(\mathrm{~m}, 2 \mathrm{H})$. ESI-MS $(\mathrm{m} / \mathrm{z})=547.01[\mathrm{M}+\mathrm{H}]^{+}$, HRMS (ESI) calcd. For $\mathrm{C}_{27} \mathrm{H}_{21} \mathrm{ClFN}_{6} \mathrm{O}_{4}{ }^{+}:[\mathrm{M}+\mathrm{H}]^{+} m / z: 547.1291$, found: 547.1279.

(S)-5-(2-(3-(3-Chloro-2-fluorophenyl)-1H-pyrazole-5-carboxamido)-3-(pyridin-3-yl)propanamido)-1H-indole2-carboxylic acid $(\mathbf{7 v})$ : grey solid product $\left(240 \mathrm{mg}, 85.3 \%\right.$ yield), m.p.: $175-17{ }^{\circ} \mathrm{C}$, decomposition. ${ }^{1} \mathrm{H}-\mathrm{NMR}$ : $\delta 13.86$ (s, 1H), 12.88 (s, 1H), 11.69 (s, 1H), 10.15 (s, 1H), 8.99 (s, 1H), 8.57 (s, 1H), 8.41-8.40 $(\mathrm{d}, J=4.4 \mathrm{~Hz}, 1 \mathrm{H}), 7.98(\mathrm{~s}, 1 \mathrm{H}), 7.88(\mathrm{~s}, 1 \mathrm{H}), 7.81-7.80(\mathrm{~d}, J=6.8 \mathrm{~Hz}, 1 \mathrm{H}), 7.52(\mathrm{~s}, 1 \mathrm{H}), 7.39-7.10(\mathrm{~m}, 4 \mathrm{H})$, $7.04(\mathrm{~s}, 1 \mathrm{H}), 4.95-4.89(\mathrm{~m}, 1 \mathrm{H}), 3.25-3.14(\mathrm{~m}, 2 \mathrm{H})$. ESI-MS $(\mathrm{m} / \mathrm{z})=547.05[\mathrm{M}+\mathrm{H}]^{+}, \mathrm{HRMS}(\mathrm{ESI})$ calcd. For $\mathrm{C}_{27} \mathrm{H}_{21} \mathrm{ClFN}_{6} \mathrm{O}_{4}{ }^{+}:[\mathrm{M}+\mathrm{H}]^{+} m / z: 547.1291$, found: 547.1272 .

(S)-5-(2-(3-(3-Chloro-2-fluorophenyl)-1H-pyrazole-5-carboxamido)-3-(pyridin-2-yl)propanamido)-1H-indole2-carboxylic acid (7w): white solid product (109 mg, 38.7\% yield), m.p.: 192-194 ${ }^{\circ} \mathrm{C}$, decomposition. ${ }^{1} \mathrm{H}-\mathrm{NMR}: \delta 11.68(\mathrm{~s}, 1 \mathrm{H}), 10.19(\mathrm{~s}, 1 \mathrm{H}), 8.71-8.70(\mathrm{~d}, J=4.4 \mathrm{~Hz}, 1 \mathrm{H}), 8.12(\mathrm{~s}, 1 \mathrm{H}), 7.97(\mathrm{~s}, 1 \mathrm{H}), 7.89-7.86$ $(\mathrm{m}, 1 \mathrm{H}),, 7.71-7.70(\mathrm{~d}, J=6.0 \mathrm{~Hz}, 1 \mathrm{H}), 7.61-7.57(\mathrm{t}, J=6.8 \mathrm{~Hz}, 2 \mathrm{H}), 7.36-7.30(\mathrm{~m}, 4 \mathrm{H}), 7.03(\mathrm{~s}, 1 \mathrm{H})$, 5.13-5.11 $(\mathrm{m}, 1 \mathrm{H}), 3.56-3.39(\mathrm{~m}, 2 \mathrm{H})$. ESI-MS $(\mathrm{m} / \mathrm{z})=547.04[\mathrm{M}+\mathrm{H}]^{+}, \mathrm{HRMS}(\mathrm{ESI})$ calcd. For $\mathrm{C}_{27} \mathrm{H}_{21} \mathrm{ClFN}_{6} \mathrm{O}_{4}{ }^{+}:[\mathrm{M}+\mathrm{H}]^{+} m / z: 547.1291$, found: 547.1275 .

(S)-Ethyl 5-(4-(tert-butoxy)-2-((tert-butoxycarbonyl)amino)-4-oxobutanamido)-1H-indole-2-carboxylate (17): To a mixture of ethyl 5-amino- $1 H$-indole-2-carboxylate $(2.00 \mathrm{~g}, 9.8 \mathrm{mmol})$, pyridine $(3.00 \mathrm{~g}, 19.6 \mathrm{mmol})$ and (S)-4-(tert-butoxy)-2-((tert-butoxycarbonyl)amino)-4-oxobutanoic acid (16, $2.83 \mathrm{~g}, 9.8 \mathrm{mmol}) \mathrm{in}$ $\mathrm{CH}_{2} \mathrm{Cl}_{2}(30 \mathrm{~mL})$ was added $\mathrm{POCl}_{3}(1.16 \mathrm{~g}, 14.7 \mathrm{mmol})$ at $-10{ }^{\circ} \mathrm{C}$ dropwise.After addition, the reaction mixture was stirred at $-10^{\circ} \mathrm{C}$ for $1 \mathrm{~h}$ when TLC analysis indicated completion of reaction. The mixture was washed by hydrochloric acid $(1 \mathrm{M}, 10 \mathrm{~mL})$, dried by $\mathrm{Na}_{2} \mathrm{SO}_{4}$ and filtered. The filtrate was evaporated in vacuum and the residue was purified on column chromatography ( $n$-hexane:ethyl acetate $=50: 1$ to $2: 1)$ to get 17 as a white solid $\left(1.77 \mathrm{~g}, 36.7 \%\right.$ yield), m.p.: $119-121{ }^{\circ} \mathrm{C}$, decomposition . ${ }^{1} \mathrm{H}-\mathrm{NMR}: \delta 11.78$ (s, 1H), 9.83 (s, 1H), 7.98 (s, 1H), $7.36(\mathrm{~s}, 2 \mathrm{H}), 7.09-7.08(\mathrm{~m}, 1 \mathrm{H}), 4.45-4.44(\mathrm{~m}, 1 \mathrm{H})$, $4.35-4.29(\mathrm{~m}, 2 \mathrm{H}), 2.69-2.65(\mathrm{~m}, 1 \mathrm{H}), 2.52-2.46(\mathrm{~m}, 1 \mathrm{H}), 1.46-1.30(\mathrm{~m}, 21 \mathrm{H})$. ESI-MS $(\mathrm{m} / z)=475.90$ $[\mathrm{M}+\mathrm{H}]^{+}, \mathrm{HRMS}(\mathrm{ESI})$ calcd. For $\mathrm{C}_{24} \mathrm{H}_{33} \mathrm{KN}_{3} \mathrm{O}_{7}{ }^{+}:[\mathrm{M}+\mathrm{K}]^{+} \mathrm{m} / z: 514.1950$, found: 514.1947 . 
(S)-3-((tert-Butoxycarbonyl)amino)-4-((2-(ethoxycarbonyl)-1H-indol-5-yl)amino)-4-oxobutanoic acid (18): To a mixture of $\mathbf{1 7}(1.7 \mathrm{~g}, 3.6 \mathrm{mmol})$ in THF $(5 \mathrm{~mL})$ was added TFA $(5 \mathrm{~mL})$ at $0{ }^{\circ} \mathrm{C}$. After addition, the mixture was stirred at room temperature for $6 \mathrm{~h}$ when TLC analysis indicated completion of reaction. The reaction mixture was evaporated in vacuum, then to the residue was added THF $(20 \mathrm{~mL}), \mathrm{H}_{2} \mathrm{O}$ $(10 \mathrm{~mL}), \mathrm{Et}_{3} \mathrm{~N}(3.6 \mathrm{~g}, 36 \mathrm{mmol})$ and $(\mathrm{Boc})_{2} \mathrm{O}(772 \mathrm{mg}, 3.6 \mathrm{mmol})$ and the reaction was stirred at room temperature overnight.TLC analysis showed the reaction was complete and the reaction mixture was evaporated in vacuum. To the residue was added $\mathrm{H}_{2} \mathrm{O}(10 \mathrm{~mL})$, extracted by $\mathrm{MTBE}(3 \mathrm{~mL})$ and acidified by hydrochloric acid $(1 \mathrm{M})$ to $\mathrm{pH}=5$. The aqueous layer was extracted by ethyl acetate for 3 times $(10 \mathrm{~mL} \times 3)$, and the combined organic layer was dried by $\mathrm{Na}_{2} \mathrm{SO}_{4}$, filtered and concentrated in vacuum to afford 18 as a grey solid (543 mg, 35.8\% yield), m.p.: $123-125{ }^{\circ} \mathrm{C}$, decomposition. ${ }^{1} \mathrm{H}-\mathrm{NMR}$ : $\delta 11.97(\mathrm{~s}, 1 \mathrm{H}), 11.77(\mathrm{~s}, 1 \mathrm{H}), 9.90(\mathrm{~s}, 1 \mathrm{H}), 7.98(\mathrm{~s}, 1 \mathrm{H}), 7.35(\mathrm{~s}, 2 \mathrm{H}), 7.10-7.08(\mathrm{~m}, 1 \mathrm{H}), 4.42-4.40(\mathrm{~m}, 1 \mathrm{H})$, 4.34-4.29 (m, 2H), 2.68-2.63 (m, 1H), 2.56-2.52 (m, 1H), 1.38-1.30 (m, 12H). ESI-MS $(m / z)=419.82$ $[\mathrm{M}+\mathrm{H}]^{+}$, HRMS (ESI) calcd. For $\mathrm{C}_{20} \mathrm{H}_{25} \mathrm{KN}_{3} \mathrm{O}_{7}{ }^{+}:[\mathrm{M}+\mathrm{K}]^{+} m / z: 458.1324$, found: 458.1322 .

(S)-Ethyl 5-(4-(4-acetylpiperazin-1-yl)-2-((tert-butoxycarbonyl)amino)-4-oxobutanamido)-1H-indole-2carboxylate (19a): To a mixture of 18 (200 mg, $0.48 \mathrm{mmol})$ in DMF (4 mL) was added 1-(piperazin-1-yl)ethanone $(61 \mathrm{mg}, 0.48 \mathrm{mmol}), N$-(3-dimethylaminopropyl)- $N$ '-ethylcarbodiimide hydrochloride (183 mg, $0.96 \mathrm{mmol})$, 1-hydroxybenzotriazole (129 mg, $0.96 \mathrm{mmol})$ and $\mathrm{N}, \mathrm{N}$-diisopropylethylamine $(185 \mathrm{mg}, 1.43 \mathrm{mmol})$. After addition, the reaction mixture was stirred at room temperature for $6 \mathrm{~h}$ when TLC analysis indicated completion of reaction. Then $\mathrm{H}_{2} \mathrm{O}(40 \mathrm{~mL})$ was added and the mixture was extracted by ethyl acetate $(15 \mathrm{~mL} \times 3)$ for 3 times. The combined organic layer was dried, filtered and the filtrate was concentrated in vacuum to get 19a as a brown solid (176.3 mg, 69.8\% yield). ${ }^{1} \mathrm{H}-\mathrm{NMR}: \delta 11.76(\mathrm{~s}, 1 \mathrm{H}), 9.81(\mathrm{~s}, 1 \mathrm{H}), 7.94(\mathrm{~s}, 1 \mathrm{H}), 7.36$ (s, 1H), 7.09-7.07 (d, J = 2.0 Hz, 1H), 6.98-6.96 (d, J = 8.0 Hz, 1H), 4.50-4.48 (m, 1H), 4.34-4.29 (m, 2H), 3.45-3.39 (m, 8H), 2.75-2.72 (m, 2H), $1.99(\mathrm{~s}, 3 \mathrm{H}), 1.37-1.30(\mathrm{~m}, 12 \mathrm{H})$. ESI-MS $(\mathrm{m} / z)=529.95[\mathrm{M}+\mathrm{H}]^{+}$.

(S)-Ethyl 5-(2-((tert-butoxycarbonyl)amino)-4-morpholino-4-oxobutanamido)-1H-indole-2-carboxylate (19b): Compounds $19 \mathrm{~b}$ were synthesized from 18 and morpholine according to the procedure described for the preparation of 19a. Grey solid product (137.2 mg, 58.9\% yield), m.p.: $144-146{ }^{\circ} \mathrm{C}$, decomposition. ${ }^{1} \mathrm{H}-\mathrm{NMR}: \delta 11.76(\mathrm{~s}, 1 \mathrm{H}), 9.81(\mathrm{~s}, 1 \mathrm{H}), 8.00(\mathrm{~s}, 1 \mathrm{H}), 7.36(\mathrm{~s}, 2 \mathrm{H}), 7.08(\mathrm{~s}, 1 \mathrm{H}), 6.96-6.94(\mathrm{~d}, \mathrm{~J}=7.2 \mathrm{~Hz}$, $1 \mathrm{H}), 4.49-4.48(\mathrm{~m}, 1 \mathrm{H}), 4.34-4.29(\mathrm{qd}, J=7.2,2 \mathrm{H}), 3.54-3.41(\mathrm{~m}, 8 \mathrm{H}), 2.72(\mathrm{~m}, 2 \mathrm{H}), 1.38-1.30(\mathrm{~m}, 12 \mathrm{H})$. ESI-MS $(m / z)=488.97[\mathrm{M}+\mathrm{H}]^{+}$, HRMS (ESI) calcd. For $\mathrm{C}_{24} \mathrm{H}_{32} \mathrm{KN}_{4} \mathrm{O}_{7}{ }^{+}:[\mathrm{M}+\mathrm{K}]^{+} m / z: 527.1903$, found: 527.1894 .

(S)-Ethyl 5-(4-(4-acetylpiperazin-1-yl)-2-(5-(3-chloro-2-fluorophenyl)-1H-pyrazole-3-carboxamido)-4oxobutanamido)-1H-indole-2-carboxylate (20a): To a mixture of 19a (170 $\mathrm{mg}, 0.32 \mathrm{mmol})$ in ethyl acetate $(1 \mathrm{~mL})$ was added hydrochloric/ethyl acetate $(10 \mathrm{~mL}$, saturated solution) and the reaction mixture was stirred at room temperature overnight. Then TLC analysis showed reaction was complete and the suspension was filtered to afford the intermediate. To the intermediate (150 $\mathrm{mg}, 0.32 \mathrm{mmo})$ in DMF (3 mL) was added 11f (78 mg, $0.32 \mathrm{mmo}), N$-(3-dimethylaminopropyl)- $N^{\prime}$-ethylcarbodiimide hydrochloride (124 mg, $0.64 \mathrm{mmol})$, 1-hydroxybenzotriazole (87 $\mathrm{mg}, 0.64 \mathrm{mmol}$ ), and $\mathrm{N}, \mathrm{N}$-diisopropylethylamine $(124 \mathrm{mg}, 0.96 \mathrm{mmol})$ and the reaction mixture was stirred at room temperature for $6 \mathrm{~h}$ when TLC analysis indicated completion of reaction. Then $\mathrm{H}_{2} \mathrm{O}(30 \mathrm{~mL})$ was added and the suspension was stirred for $10 \mathrm{~min}$, filtered, dried at $50{ }^{\circ} \mathrm{C}$ for $4 \mathrm{~h}$ to get $20 \mathrm{a}$ as a brown solid (91.2 mg, 43.3\% yield), m.p.:156-158 ${ }^{\circ} \mathrm{C}$, decomposition. ${ }^{1} \mathrm{H}-\mathrm{NMR}: \delta 13.94(\mathrm{~m}, 1 \mathrm{H}), 11.78(\mathrm{~s}, 1 \mathrm{H})$, 10.04-9.91 (m, 1H), 8.80-8.78 (m, 1H), $8.01(\mathrm{~s}, 1 \mathrm{H}), 7.94-7.82(\mathrm{~m}, 1 \mathrm{H}), 7.62-7.54(\mathrm{~m}, 1 \mathrm{H}), 7.44-7.11$ $(\mathrm{m}, 4 \mathrm{H}), 7.08(\mathrm{~s}, 1 \mathrm{H}), 5.00(\mathrm{~s}, 1 \mathrm{H}), 4.36-4.29(\mathrm{~m}, 2 \mathrm{H}), 3.58-3.39(\mathrm{~m}, 8 \mathrm{H}), 2.93-2.88(\mathrm{~m}, 2 \mathrm{H}), 1.97(\mathrm{~s}, 3 \mathrm{H})$, 1.34-1.30 (m, 3H). ESI-MS $(m / z)=651.97[\mathrm{M}+\mathrm{H}]^{+}$, HRMS (ESI) calcd. For $\mathrm{C}_{31} \mathrm{H}_{32} \mathrm{ClFN}_{7} \mathrm{O}_{6}{ }^{+}:[\mathrm{M}+\mathrm{H}]^{+}$ $m / z: 652.2081$, found: 652.2070 .

(S)-Ethyl 5-(2-(5-(3-chloro-2-fluorophenyl)-1H-pyrazole-3-carboxamido)-4-morpholino-4-oxobutanamido)-1Hindole-2-carboxylate (20b): Compounds $20 \mathrm{~b}$ were synthesized from $\mathbf{1 9 b}$ and $\mathbf{1 1 f}$ according to the 
procedure described for the preparation of 20a. Grey solid product (90.3 mg, 52.2 \% yield), m.p.:136-138 ${ }^{\circ} \mathrm{C}$, decomposition. ${ }^{1} \mathrm{H}-\mathrm{NMR}: \delta 13.90(\mathrm{~s}, 1 \mathrm{H}), 11.78(\mathrm{~s}, 1 \mathrm{H}), 9.98(\mathrm{~s}, 1 \mathrm{H}), 8.01(\mathrm{~s}, 1 \mathrm{H}), 7.88(\mathrm{~s}, 1 \mathrm{H})$, 7.60-7.53 (m, 2H), 7.41-7.30 (m, 4H), $7.08(\mathrm{~s}, 1 \mathrm{H}), 5.03-4.97(\mathrm{~m}, 1 \mathrm{H}), 4.38-4.29(\mathrm{~m}, 2 \mathrm{H}), 3.63-3.38(\mathrm{~m}$, $8 \mathrm{H}), 2.93-2.80(\mathrm{~m}, 2 \mathrm{H}), 1.38-1.30(\mathrm{~m}, 3 \mathrm{H})$. ESI-MS $(m / z)=610.95[\mathrm{M}+\mathrm{H}]^{+}$, HRMS (ESI) calcd. For $\mathrm{C}_{29} \mathrm{H}_{29} \mathrm{ClFN}_{6} \mathrm{O}_{6}{ }^{+}:[\mathrm{M}+\mathrm{H}]^{+} m / z: 611.1806$, found: 611.1811 .

(S)-5-(4-(4-Acetylpiperazin-1-yl)-2-(5-(3-chloro-2-fluorophenyl)-1H-pyrazole-3-carboxamido)-4-oxobutanamido) -1H-indole-2-carboxylic acid (7x): To a mixture of $20 \mathrm{a}(85 \mathrm{mg}, 0.13 \mathrm{mmol})$ in EtOH $(4 \mathrm{~mL})$ and $\mathrm{H}_{2} \mathrm{O}$ $(2 \mathrm{~mL})$ was added $\mathrm{LiOH} \cdot \mathrm{H}_{2} \mathrm{O}(40 \mathrm{mg}, 0.95)$ and the reaction mixture was stirred at room temperature for $5 \mathrm{~h}$ when TLC analysis indicated completion of reaction. The mixture was evaporated on a rotary evaporator in vacuum, then the residue was acidified by hydrochloric acid (1 M) to $\mathrm{pH} 3-4$ and filtered. The filter cake was dried at $50{ }^{\circ} \mathrm{C}$ for $4 \mathrm{~h}$ to get $7 \mathbf{x}$ as a white solid $(62 \mathrm{mg}, 76.4 \%$ yield), m.p.: 101-103 ${ }^{\circ} \mathrm{C}$, decomposition. ${ }^{1} \mathrm{H}-\mathrm{NMR}(400 \mathrm{MHz}, \mathrm{DMSO}-\mathrm{d} 6): \delta 13.94(\mathrm{~s}, 1 \mathrm{H}), 11.63(\mathrm{~s}, 1 \mathrm{H}), 10.00(\mathrm{~s}, 1 \mathrm{H})$, $7.98(\mathrm{~s}, 1 \mathrm{H}), 7.89(\mathrm{~s}, 1 \mathrm{H}), 7.58(\mathrm{~s}, 1 \mathrm{H}), 7.43-7.32(\mathrm{~m}, 4 \mathrm{H}), 7.01(\mathrm{~s}, 1 \mathrm{H})$, 5.01-5.00 (m, 1H), 3.57-3.47 $(\mathrm{m}, 6 \mathrm{H}), 2.95-2.85(\mathrm{~m}, 4 \mathrm{H}), 2.00(\mathrm{~s}, 3 \mathrm{H})$. ESI-MS $(\mathrm{m} / \mathrm{z})=623.94[\mathrm{M}+\mathrm{H}]^{+}, \mathrm{HRMS}(\mathrm{ESI})$ calcd. For $\mathrm{C}_{29} \mathrm{H}_{28} \mathrm{ClFN}_{7} \mathrm{O}_{6}^{+}:[\mathrm{M}+\mathrm{H}]^{+} m / z: 624.1768$, found: 624.1755 .

(S)-5-(2-(3-(3-Chloro-2-fluorophenyl)-1H-pyrazole-5-carboxamido)-4-morpholino-4-oxobutanamido)-1H-indole -2-carboxylic acid (7y): Compounds $7 \mathbf{y}$ were synthesized from $\mathbf{2 0 b}$ according to the procedure described for the preparation of $7 \mathbf{x}$. White solid product $\left(59 \mathrm{mg}, 77.8 \%\right.$ yield), m.p.: $175-177{ }^{\circ} \mathrm{C}$, decomposition. ${ }^{1} \mathrm{H}-\mathrm{NMR}: \delta 13.95-13.84(\mathrm{~m}, 1 \mathrm{H}), 11.62-11.60(\mathrm{~m}, 1 \mathrm{H}), 10.01-9.98(\mathrm{~m}, 1 \mathrm{H}), 8.81(\mathrm{~s}, 1 \mathrm{H}), 8.38-8.36(\mathrm{~m}, 1 \mathrm{H})$, $7.98(\mathrm{~s}, 1 \mathrm{H}), 7.90-7.82(\mathrm{~m}, 1 \mathrm{H}), 7.58(\mathrm{~s}, 1 \mathrm{H}), 7.48-7.28(\mathrm{~m}, 3 \mathrm{H}), 7.00(\mathrm{~s}, 1 \mathrm{H}), 5.01-4.92(\mathrm{~m}, 1 \mathrm{H}), 3.57-3.42$ $(\mathrm{m}, 4 \mathrm{H}), 3.39-3.29(\mathrm{~m}, 4 \mathrm{H}), 2.96-2.92(\mathrm{~m}, 2 \mathrm{H})$. ESI-MS $(m / z)=582.96[\mathrm{M}+\mathrm{H}]^{+}$, HRMS (ESI) calcd. For $\mathrm{C}_{27} \mathrm{H}_{26} \mathrm{ClFN}_{6} \mathrm{O}_{6}{ }^{+}:[\mathrm{M}+\mathrm{H}]^{+} m / z: 583.1503$, found: 583.1485 .

(S)-2-(5-(3-Chloro-2-fluorophenyl)-1H-pyrazole-3-carboxamido)-3-(4-nitrophenyl)propanoic acid (22): A mixture of 3-(3-chloro-2-fluorophenyl)-1H-pyrazole-5-carboxylic acid (11f, $2.2 \mathrm{~g}, 8.43 \mathrm{mmol}$ ), (S)-methyl 2-amino-3-(4-nitrophenyl)propanoate (21, $2.0 \mathrm{~g}, 8.43 \mathrm{mmol}), 1$-hydroxybenzotriazole $(2.3 \mathrm{~g}, 17.04 \mathrm{mmol}), \quad N$-(3-dimethylaminopropyl)- $N^{\prime}$-ethylcarbodiimide hydrochloride (3.2 g, $17.04 \mathrm{mmol})$ and $N, N$-diisopropylethylamine $(3.2 \mathrm{~g}, 24.80 \mathrm{mmol})$ in DMF $(20 \mathrm{~mL})$ was stirred at room temperature overnight. Then TLC analysis showed reaction was complete and $\mathrm{H}_{2} \mathrm{O}(200 \mathrm{~mL})$ was added, then the suspension was stirred for $0.5 \mathrm{~h}$ andfiltered. The filter cake was transferred to a round-bottomed flask, and $\mathrm{MeOH}(60 \mathrm{~mL}), \mathrm{H}_{2} \mathrm{O}(30 \mathrm{~mL})$ and $\mathrm{LiOH} \cdot \mathrm{H}_{2} \mathrm{O}(1.0 \mathrm{~g}, 23.8 \mathrm{mmol})$ was added. The reaction mixture was stirred at room temperature for $2 \mathrm{~h}$ when TLC analysis indicated completion of reaction, evaporated on a rotary evaporator in vacuum, then $\mathrm{H}_{2} \mathrm{O}(50 \mathrm{~mL})$ was added, acidified by hydrochloric acid ( $1 \mathrm{M}$ ) to $\mathrm{pH}$ 3-4 and filtered.The filter cake was dried at $50{ }^{\circ} \mathrm{C}$ for $8 \mathrm{~h}$ to afford 22 as a yellow solid (3.25 g, 89.0\% yield), m.p.: $167-169{ }^{\circ} \mathrm{C}$, decomposition. ${ }^{1} \mathrm{H}-\mathrm{NMR}: \delta 14.01-13.79$ $(\mathrm{m}, 1 \mathrm{H}), 8.11-8.02(\mathrm{~m}, 2 \mathrm{H}), 7.87-7.84(\mathrm{~m}, 1 \mathrm{H}), 7.59-7.56(\mathrm{~m}, 1 \mathrm{H}), 7.49-7.42(\mathrm{~m}, 2 \mathrm{H}), 7.36-7.22(\mathrm{~m}, 1 \mathrm{H})$, $7.06(\mathrm{~s}, 1 \mathrm{H}), 4.42-4.29(\mathrm{~m}, 1 \mathrm{H}), 3.32-3.19(\mathrm{~m}, 2 \mathrm{H})$. ESI-MS $(\mathrm{m} / z)=432.94[\mathrm{M}+\mathrm{H}]^{+}$, HRMS (ESI) calcd. For $\mathrm{C}_{19} \mathrm{H}_{15} \mathrm{ClFN}_{4} \mathrm{O}_{5}{ }^{+}:[\mathrm{M}+\mathrm{H}]^{+} m / z: 433.0710$, found: 433.0708 .

(S)-Ethyl 5-(3-(4-aminophenyl)-2-(5-(3-chloro-2-fluorophenyl)-1H-pyrazole-3-carboxamido)propanamido)-1H -indole-2-carboxylate (23): A mixture of compound $22(3.00 \mathrm{~g}, 6.93 \mathrm{mmol})$, ethyl 5-amino-1H-indole-2-carboxylate $(1.42 \mathrm{~g}), \quad N$-(3-dimethylaminopropyl)- $N$ '-ethylcarbodiimide hydrochloride (2.66 g, $13.9 \mathrm{mmol})$, 1-hydroxybenzotriazole (1.87 g, $13.9 \mathrm{mmol})$ and $\mathrm{N}, \mathrm{N}$-diisopropylethylamine $(1.79 \mathrm{~g}, 13.9 \mathrm{mmol})$ in $\mathrm{DMF}(20 \mathrm{~mL})$ was stirred at room temperature overnight when TLC analysis indicated completion of reaction, then $\mathrm{H}_{2} \mathrm{O}(200 \mathrm{~mL})$ was added. The suspension was stirred for $10 \mathrm{~min}$ and filtered. The filter cake was dried at room temperature overnight and resolve in $\mathrm{MeOH}(200 \mathrm{~mL})$ and ethyl acetate $(100 \mathrm{~mL})$. To the solution was added $\mathrm{Pd} / \mathrm{C}(10 \%, 0.30 \mathrm{~g})$ and the reaction mixture was stirred at the atmosphere of $\mathrm{H}_{2}$ overnight when TLC analysis indicated completion of reaction. The suspension was filtered and the filtrate was concentrated in vacuum to afford intermediate 23 as a grey solid ( $3.1 \mathrm{~g}, 75.6 \%$ yield), m.p.: $120-122{ }^{\circ} \mathrm{C}$, 
decomposition. ${ }^{1} \mathrm{H}-\mathrm{NMR}: \delta 13.77$ (s, 1H), 11.80 (s, 1H), $10.20(\mathrm{~s}, 1 \mathrm{H}), 8.99-8.69$ (m, 2H), $7.99(\mathrm{~s}, 1 \mathrm{H})$, $7.91(\mathrm{~s}, 1 \mathrm{H}), 7.38-6.98(\mathrm{~m}, 7 \mathrm{H}), 6.91(\mathrm{~s}, 1 \mathrm{H}), 6.81-6.80(\mathrm{~d}, J=2.4 \mathrm{~Hz}, 2 \mathrm{H}), 4.88-4.86(\mathrm{~m}, 1 \mathrm{H}), 4.34-4.29$ $(\mathrm{qd}, J=6.8 \mathrm{~Hz}, 2 \mathrm{H}), 3.17-3.10(\mathrm{~m}, 2 \mathrm{H}), 1.34-1.31$ (m, 3H). ${ }^{13} \mathrm{C}-\mathrm{NMR}: \delta 170.51,161.92,147.33,135.04$, 132.57, 130.40, 128.58, 127.48, 127.26, 126.30, 125.51, 119.84, 114.71, 113.25, 112.79, 108.33, 106.65, $61.05,54.03,40.76,14.94$. ESI-MS $(m / z)=588.98[\mathrm{M}+\mathrm{H}]^{+}, \mathrm{HRMS}(\mathrm{ESI})$ calcd. For $\mathrm{C}_{30} \mathrm{H}_{27} \mathrm{ClFN}_{6} \mathrm{O}_{4}{ }^{+}$: $[\mathrm{M}+\mathrm{H}]^{+} m / z: 589.1688$, found: 589.1755 .

(S)-5-(3-(4-Aminophenyl)-2-(5-(3-chloro-2-fluorophenyl)-1H-pyrazole-3-carboxamido)propanamido)-1H-indole -2-carboxylic acid (7z): To a mixture of compound $23(140 \mathrm{mg}, 0.24 \mathrm{mmol})$ in $\mathrm{MeOH}(4 \mathrm{~mL})$ and $\mathrm{H}_{2} \mathrm{O}$ $(2 \mathrm{~mL})$ was added $\mathrm{LiOH} \cdot \mathrm{H}_{2} \mathrm{O}(52 \mathrm{mg}, 1.20 \mathrm{mmol})$ and the mixture was stirred at $40{ }^{\circ} \mathrm{C}$ for $4 \mathrm{~h}$ when TLC analysis indicated completion of reaction. The mixture was concentrated and $\mathrm{H}_{2} \mathrm{O}(2 \mathrm{~mL})$ was added. The solution was acidified with hydrochloric acid $(1 \mathrm{M})$ to $\mathrm{pH}=5$, filtered and the filter cake was washed by $\mathrm{H}_{2} \mathrm{O}(2 \mathrm{~mL})$, dried at $50{ }^{\circ} \mathrm{C}$ for $3 \mathrm{~h}$ to afford $7 \mathbf{z}$ as a brown solid $(98.0 \mathrm{mg}, 72.8 \%$ yield), m.p.: $209-211^{\circ} \mathrm{C}$, decomposition. ${ }^{1} \mathrm{H}-\mathrm{NMR}$ : $\delta$ 13.88-13.86 (m, 1H), $11.64(\mathrm{~s}, 1 \mathrm{H}), 10.10-10.04(\mathrm{~m}, 1 \mathrm{H})$, $8.82(\mathrm{~s}, 1 \mathrm{H}), 7.96(\mathrm{~s}, 1 \mathrm{H}), 7.89(\mathrm{~s}, 1 \mathrm{H}), 7.58(\mathrm{~s}, 1 \mathrm{H}), 7.57-7.29(\mathrm{~m}, 6 \mathrm{H}), 7.22-6.98(\mathrm{~m}, 3 \mathrm{H}), 6.45-6.43$ $(\mathrm{d}, J=8.0 \mathrm{~Hz}, 2 \mathrm{H}), 4.80-4.74(\mathrm{~m}, 1 \mathrm{H}), 3.02-2.92(\mathrm{~m}, 2 \mathrm{H})$. ESI-MS $(m / z)=560.92[\mathrm{M}+\mathrm{H}]^{+}, \mathrm{HRMS}(\mathrm{ESI})$ calcd. For $\mathrm{C}_{28} \mathrm{H}_{23} \mathrm{ClFN}_{6} \mathrm{O}_{4}{ }^{+}:[\mathrm{M}+\mathrm{H}]^{+} m / z$ : 561.1448, found: 561.1439.

Ethyl 5-((2S)-2-(5-(3-chloro-2-fluorophenyl)-1H-pyrazole-3-carboxamido)-3-(4-(2-methylcyclopropane-carboxamido) phenyl)propanamido)-1H-indole-2-carboxylate (24za): To a mixture of compound 23 (200 $\mathrm{mg}, 0.34 \mathrm{mmol}$ ), 2-methylcyclopropanecarboxylic acid (34 mg, $0.34 \mathrm{mmol}$ ) and pyridine (54 mg, $0.68 \mathrm{mmol})$ in $\mathrm{CH}_{2} \mathrm{Cl}_{2}$ $(5 \mathrm{~mL})$ was added $\mathrm{POCl}_{3}(78 \mathrm{mg}, 0.51 \mathrm{mmol})$ at $-10{ }^{\circ} \mathrm{C}$ dropwise. After addition, the reaction mixture was stirred at $-10^{\circ} \mathrm{C}$ for $1 \mathrm{~h}$ when TLC analysis indicated completion of reaction. The mixture was added $\mathrm{H}_{2} \mathrm{O}(0.5 \mathrm{~mL})$, concentrated in vacuum, and the residue was purified by Prep-TLC to afford desired product $24 \mathrm{za}$ as a brown solid $\left(76 \mathrm{mg}, 33.3 \%\right.$ yield), m.p.: $227-229{ }^{\circ} \mathrm{C}$, decomposition. ${ }^{1} \mathrm{H}-\mathrm{NMR}$ : $\delta 13.85$ (s, 1H), 11.80 (s, 1H), 10.10 (s, 1H), 9.99 (s, 1H), 7.98 (s, 1H), 7.91 (s, 1H), 7.57 (s, 1H), 7.48-7.10 $(\mathrm{m}, 9 \mathrm{H}), 7.05(\mathrm{~s}, 1 \mathrm{H}), 4.86-4.85(\mathrm{~m}, 1 \mathrm{H}), 4.35-4.29(\mathrm{qd}, J=6.8 \mathrm{~Hz}, 2 \mathrm{H}), 3.12-3.02(\mathrm{~m}, 2 \mathrm{H}), 1.46-1.45(\mathrm{~m}, 1 \mathrm{H})$, $1.34-1.31(\mathrm{~m}, 3 \mathrm{H}), 1.22-1.16(\mathrm{~m}, 1 \mathrm{H}), 1.08-1.05(\mathrm{~m}, 3 \mathrm{H}), 0.96-0.94(\mathrm{~m}, 1 \mathrm{H}), 0.58(\mathrm{~s}, 1 \mathrm{H})$. ESI-MS $(\mathrm{m} / z)=$ $670.92[\mathrm{M}+\mathrm{H}]^{+}, \mathrm{HRMS}(\mathrm{ESI})$ calcd. For $\mathrm{C}_{35} \mathrm{H}_{33} \mathrm{ClFN}_{6} \mathrm{O}_{5}{ }^{+}:[\mathrm{M}+\mathrm{H}]^{+} m / z: 671.2180$, found: 671.2178 .

5-((2S)-2-(5-(3-Chloro-2-fluorophenyl)-1H-pyrazole-3-carboxamido)-3-(4-(2-methylcyclopropane-carboxamido) phenyl)propanamido)-1H-indole-2-carboxylic acid (7za): Compounds 7za was synthesized from compound $\mathbf{2 4 z a}$ according to the procedure described for the preparation of $\mathbf{7 z}$. Grey solid product $(45 \mathrm{mg}, 63.7 \%$ yield), m.p.: $212-214{ }^{\circ} \mathrm{C}$, decomposition. ${ }^{1} \mathrm{H}-\mathrm{NMR}: \delta 13.85$ (s, 1H), 12.83 (s, 1H), 11.67 (s, $\left.1 \mathrm{H}\right), 10.12$ $(\mathrm{s}, 1 \mathrm{H}), 8.12(\mathrm{~s}, 1 \mathrm{H}), 7.98(\mathrm{~s}, 1 \mathrm{H}), 7.60-7.57(\mathrm{~m}, 1 \mathrm{H}), 7.52-7.04(\mathrm{~m}, 6 \mathrm{H}), 7.03(\mathrm{~s}, 1 \mathrm{H}), 4.88-4.70(\mathrm{~m}, 1 \mathrm{H})$, 3.14-3.01 (m, 2H), 1.48-1.44 (m, 1H), 1.21-1.17(m, 1H), 1.16-1.08 (m, 3H), 1.06-1.04 (m, 1H), 0.56-0.59 (m, 1H). ${ }^{13} \mathrm{C}-\mathrm{NMR}: \delta 171.23,169.68,162.96,155.35,152.85,138.12,137.95,134.30,132.17,131.71,130.05$, 129.56, 126.92, 125.71, 120.90, 120.73, 118.80, 112.57, 112.21, 107.24, 106.11, 55.26, 37.26, 23.07, 17.61, 15.21, 11.90. ESI-MS $(m / z)=642.92[\mathrm{M}+\mathrm{H}]^{+}$, HRMS $(\mathrm{ESI})$ calcd. For $\mathrm{C}_{33} \mathrm{H}_{29} \mathrm{ClFN}_{6} \mathrm{O}_{5}{ }^{+}:[\mathrm{M}+\mathrm{H}]^{+} m / z$ : 643.1867, found: 643.1848 .

(S)-Ethyl 5-(2-(5-(3-chloro-2-fluorophenyl)-1H-pyrazole-3-carboxamido)-3-(4-(4-methylpiperazine-1-carboxamido) phenyl)propanamido)-1H-indole-2-carboxylate (24zb): A mixture of compound 23 (300 mg, $0.51 \mathrm{mmol}$ ), pyridine (403 mg, $5.1 \mathrm{mmol}$ ), 4-methylpiperazine-1-carbonyl chloride hydrochloride (166 mg, $1.02 \mathrm{mmol}$ ), and 4-dimethylaminopyridine $(13 \mathrm{mg}, 0.10 \mathrm{mmol})$ in DMF $(5 \mathrm{~mL})$ was stirred at room temperature overnight when TLC analysis indicated completion of reaction. The mixture was added $\mathrm{H}_{2} \mathrm{O}(40 \mathrm{~mL})$ and extracted by ethyl acetate for 3 times $(15 \mathrm{~mL} \times 3)$. The combined organic layer was dried and concentrated in vacuum to get intermediate $24 \mathrm{zb}(223 \mathrm{mg}, 60.8 \%$ yield $)$, m.p.: $174-176{ }^{\circ} \mathrm{C}$, decomposition. ${ }^{1} \mathrm{H}-\mathrm{NMR}$ : $\delta 13.86(\mathrm{~s}, 1 \mathrm{H}), 11.80(\mathrm{~s}, 1 \mathrm{H}), 10.14(\mathrm{~s}, 1 \mathrm{H}), 8.44(\mathrm{~s}, 1 \mathrm{H}), 7.99-7.89(\mathrm{~m}, 2 \mathrm{H}), 7.58(\mathrm{~s}, 1 \mathrm{H}), 7.49-7.34(\mathrm{~m}, 6 \mathrm{H})$, 7.32-7.21 (m, 2H), 7.09 (s, 1H), 4.86-4.84 (m, 1H), 4.34-4.29 (qd, J = 7.2 Hz, 2H), 3.60-3.04 (m, 10H), 2.29 $(\mathrm{s}, 3 \mathrm{H}), 1.34-1.31(\mathrm{~m}, 3 \mathrm{H}$,$) . ESI-MS (\mathrm{m} / z)=715.22[\mathrm{M}+\mathrm{H}]^{+}, \mathrm{HRMS}(\mathrm{ESI})$ calcd. For $\mathrm{C}_{36} \mathrm{H}_{37} \mathrm{ClFN}_{8} \mathrm{O}_{5}{ }^{+}$: $[\mathrm{M}+\mathrm{H}]^{+} m / z: 715.2554$, found: 715.2543 . 
(S)-5-(2-(5-(3-Chloro-2-fluorophenyl)-1H-pyrazole-3-carboxamido)-3-(4-(4-methylpiperazine-1-carboxamido) phenyl)propanamido)-1H-indole-2-carboxylic acid (7zb): Compound $\mathbf{7 z b}$ was synthesized from compound $\mathbf{2 4 z b}$ according to the procedure described for the preparation of $\mathbf{7 z}$. Grey solid product $(153 \mathrm{mg}$, 73.4\% yield), m.p.: $203-205{ }^{\circ} \mathrm{C}$, decomposition. ${ }^{1} \mathrm{H}-\mathrm{NMR}: \delta 13.88(\mathrm{~s}, 1 \mathrm{H}), 11.66(\mathrm{~s}, 1 \mathrm{H}), 10.10(\mathrm{~s}, 1 \mathrm{H})$, $8.44(\mathrm{~s}, 1 \mathrm{H}), 7.97(\mathrm{~s}, 1 \mathrm{H}), 7.88(\mathrm{~s}, 1 \mathrm{H}), 7.58(\mathrm{~s}, 1 \mathrm{H}), 7.38-7.20(\mathrm{~m}, 9 \mathrm{H}), 7.03(\mathrm{~s}, 1 \mathrm{H}), 4.86-4.85(\mathrm{~m}, 1 \mathrm{H})$, 3.48-3.44 (m, 6H), 3.13-3.02 (m, 4H), $2.30(3 \mathrm{H}, \mathrm{s})$. ESI-MS $(\mathrm{m} / \mathrm{z})=687.11[\mathrm{M}+\mathrm{H}]^{+}$, HRMS (ESI) calcd. For $\mathrm{C}_{34} \mathrm{H}_{33} \mathrm{ClFN}_{8} \mathrm{O}_{5}{ }^{+}:[\mathrm{M}+\mathrm{H}]^{+} m / z$ : 687.2241, found: 687.2222.

(S)-Ethyl 5-(2-(5-(3-chloro-2-fluorophenyl)-1H-pyrazole-3-carboxamido)-3-(4-(3-oxomorpholino)phenyl)propanamido)-1H-indole-2-carboxylate (24zc): A mixture of 2-(2-chloroethoxy)acetic acid (48 $\mathrm{mg}$, $0.34 \mathrm{mmol}$ ), compound 23 (200 $\mathrm{mg}, 0.34 \mathrm{mmol}$ ) and $N$-ethoxycarbonyl-2-ethoxy-1,2-dihydroquinoline $(100 \mathrm{mg}, 0.41 \mathrm{mmol})$ in THF $(4 \mathrm{~mL})$ was stirred at $60^{\circ} \mathrm{C}$ for $4 \mathrm{~h}$ when TLC analysis indicated completion of reaction. The reaction mixture was concentrated in vacuum and THF $(5 \mathrm{~mL})$ was added to the residue. To the stirred mixture was added $\mathrm{NaH}(40 \mathrm{mg}, 1 \mathrm{mmol})$ in portions at room temperature. After addition, the mixture was stirred at room temperature for $5 \mathrm{~h}$ and TLC showed reaction was complete. Then $\mathrm{NH}_{4} \mathrm{Cl}$ solution $(0.2 \mathrm{~mL}$, concentrated solution) was added and the mixture was concentrated in vacuum. The residue was recrystallized fromn-hexane and ethyl acetate to give $24 \mathrm{zc}$ as a brown solid (174 mg, 76.0\% yield). ${ }^{1} \mathrm{H}-\mathrm{NMR}: \delta 11.84(\mathrm{~s}, 1 \mathrm{H}), 10.45-10.39(\mathrm{~m}, 1 \mathrm{H}), 8.47(\mathrm{~s}, 3 \mathrm{H}), 8.02(\mathrm{~s}, 2 \mathrm{H}), 7.41-7.39$ $(\mathrm{m}, 3 \mathrm{H}), 7.28-7.26(\mathrm{~m}, 3 \mathrm{H}), 7.23-7.19(\mathrm{~m}, 2 \mathrm{H}), 4.90(\mathrm{~m}, 1 \mathrm{H}), 4.34-4.28(\mathrm{qd}, J=7.2 \mathrm{~Hz}, 2 \mathrm{H}), 3.92-3.89$ $(\mathrm{m}, 2 \mathrm{H}), 3.68-3.59(\mathrm{~m}, 2 \mathrm{H}), 3.40-3.38(\mathrm{~m}, 2 \mathrm{H}), 3.17-3.07(\mathrm{~m}, 2 \mathrm{H}), 1.33-1.30(\mathrm{t}, J=7.2 \mathrm{~Hz}, 3 \mathrm{H})$. ESI-MS $(m / z)=695.17[\mathrm{M}+\mathrm{Na}]^{+}$.

(S)-5-(2-(5-(3-Chloro-2-fluorophenyl)-1H-pyrazole-3-carboxamido)-3-(4-(3-oxomorpholino)phenyl)-propanamido) -1H-indole-2-carboxylic acid (7zc): Compounds $7 \mathbf{z c}$ was synthesized from compound $24 \mathbf{z c}$ according to the procedure described for the preparation of $7 \mathbf{z}$. Grey solid product $(78.0 \mathrm{mg}, 50.4 \%$ yield), m.p.: 200-202 ${ }^{\circ} \mathrm{C}$, decomposition. ${ }^{1} \mathrm{H}-\mathrm{NMR}: \delta 13.89$ (s, 1H), $11.18(\mathrm{~s}, 1 \mathrm{H}), 10.14(\mathrm{~s}, 1 \mathrm{H}), 7.92-7.88$ (m, 2H), 7.56-7.41 (m, 2H), 7.39-7.25 (m, 6H), 4.90-4.89 (m, 1H), $4.15(\mathrm{~s}, 2 \mathrm{H}), 3.93-3.90(\mathrm{~m}, 2 \mathrm{H}), 3.68-3.66$ (m, 2H), 3.57-3.55 (m, 2H). ESI-MS $(m / z)=644.90[\mathrm{M}+\mathrm{H}]^{+}$, HRMS (ESI) calcd. For $\mathrm{C}_{32} \mathrm{H}_{27} \mathrm{ClFN}_{6} \mathrm{O}_{6}{ }^{+}:[\mathrm{M}+\mathrm{H}]^{+}$ $m / z: 645.1659$, found: 645.1637 .

\subsection{Inhibition of FXIa In Vitro}

The inhibition of FXIa in vitro was measured using human FXIa (Haematologic Technologies, Essex Junction, VT, USA) and Activated Protein C Chromogenic substrate BIOPHEN CS-21(66) (HYPHEN BioMed, NEUVILLE-SUR-OISE, France) in 96-well microtiter plates at $37^{\circ} \mathrm{C}$. The target compounds and compound 4 was dissolved, diluted in DMSO and analyzed at a final concentration range of $6.5 \mathrm{nM}$ to $84.5 \mu \mathrm{M}$ respectively. To the 96-well microtiter plates was added $15 \mu \mathrm{L}$ test compound, $15 \mu \mathrm{L}$ FXIa (37.5 pM) and $100 \mu \mathrm{L}$ Tris buffer (adjust to pH 7.4 with hydrochloric acid containing $0.3 \mathrm{M} \mathrm{NaCl}$ and $50 \mathrm{mM}$ Tris) in turn respectively. The negative controlwas composed of the same mixed solutions except replacing test compound with DMSO. The positivecontrol was composed of the same mixed solutions except replacing test compound with compound 4. After incubated for 5 min at $37^{\circ} \mathrm{C}$, Activated Protein C Chromogenic substrate $(30 \mu \mathrm{L}, 435 \mu \mathrm{M})$ was added and the mixture was incubated at $37^{\circ} \mathrm{C}$. The FXIa inhibitory activity was measured at $405 \mathrm{~nm}$ using a Spectra Max M5 (Molecular Devices, Sunnyvale, CA, USA). The IC $_{50}$ was calculated by IBM SPSS Statistics 22.0 (IBM Inc., North Castle, NY, USA) and the Probit function in it. $\mathbf{I C}_{\mathbf{5 0}}$ values were converted to Ki values by the followingrelationship:

$$
\mathrm{Ki}=\mathrm{IC}_{50} /(1+[\mathrm{S}] / \mathrm{Km})
$$

\section{4. aPTT In Vitro Coagulation Assays}

A commercially available automatic Coagulation analyzer (Steellex Science Instrument Co., Ltd., Beijing, China) was employed to measure aPTT. The clotting times were also measured using the 
instrument itself, in accordance with the manufacturer's instructions. Increasing concentrations of inhibitor or solvent were added to rabbit (Beijing Longan Experimental Animal Breeding Center, SCXK(Jing)2016-0006, Beijing, China) plasma and incubated for $3 \mathrm{~min}$ at $37^{\circ} \mathrm{C}$. APTT was determined by automatic Coagulation analyzer.

\subsection{Molecular Docking Method}

The structure of FXIa receptor was taken from Protein Data Bank with the ID code 5E2O. The receptor was processed using Protein Preparation Wizard, which included solvent deletion, hydrogen addition, bond order assignment and disulfide treatment. The original ligand 5JM was used as the docking center to generate the receptor grid file with a box size of $15 \AA$. The designed compounds were prepared using LigPrep module, and Epik method was used to determine the possible ionization state at $\mathrm{pH}=7.0 \pm 2.0$ with OPLS-2005 force field. Molecular docking calculations were carried out using Glide with default parameters at standard precision. All these calculations were performed in Schrödinger 2009 software (Glide version 5.5, Schrödinger, New York, NY, USA).

\section{Conclusions}

In summary, we defined 5-phenyl-1H-pyrazole-3-carboxylic acid derivatives as privileged fragments and assembled them into $\mathbf{7 a - 7 z c}$ as pharmacophore for FXIa inhibitors. We synthesized and assessed the FXIa inhibitory potency of a series of 5-phenyl- $1 H$-pyrazole-3-carboxamide derivatives. Finally, the SAR of them was systemically investigated to afford the lead compound 7za $($ FXIa Ki $=90.37 \mathrm{nM}, 1.5 \times$ aPTT in rabbit plasma $=43.33 \mu \mathrm{M})$ which exhibited good in vitro inhibitory potency against FXIa and excellent in vitro coagulation activity and lead optimization is ongoing in our lab. Furthermore, the binding mode of 7za with FXIawas studied and the results suggest that the 2-methylcyclopropanecarboxamide group of $\mathbf{7 z a}$ forms twodirect hydrogen bonds with Tyr58B and Thr35 in the FXIa backbone, making 7za bind to FXIa in a highly efficient manner.

Author Contributions: Q.W. and Z.Z. conceived, designed and performed the synthetic experiment part; F.M. conceived, designed and performed the docking simulation study part; S.Z., X.Z. and J.Y. conceived, designed and performed the pharmacological test part; Q.W. wrote the paper; Y.X., C.H. assisted paper revision.

Funding: This research was funded by Tianjin Natural Science Foundation-Young Foundation (No. 17JCQNJC13700 and 17JCQNJC13100).

Conflicts of Interest: The authors declare no conflict of interest.

\section{References}

1. Raskob, G.E.; Angchaisuksiri, P.; Blanco, A.N.; Büller, H.; Gallus, A.; Hunt, B.J.; Hylek, E.M.; Kakkar, T.L.; Konstantinides, S.V.; McCumber, M. Thrombosis: A major contributorto global disease burden. Semin. Thromb. Hemost. 2014, 40, 724-735. [CrossRef] [PubMed]

2. Mahan, C.E.; Holdsworth, M.T.; Welch, S.M.; Borrego, M.; Spyropoulos, A.C. Deep-vein thrombosis:A United States cost model for a preventable and costly adverseevent. Thromb. Haemost. 2011, 106, 405-415. [CrossRef] [PubMed]

3. Broussalis, E.; Anna, W.; Trinka, E.; Mutzenbach, S.; Killer, M. Latest developments in anticoagulant drug discovery. Drug Discov. Today 2014, 19, 921-935. [CrossRef] [PubMed]

4. Chen, Z.; Seiffert, D.; Hawes, B. Inhibition of factor XIa activity as a promising antithrombotic strategy. Drug Discov. Today 2014, 19, 1435-1439. [CrossRef] [PubMed]

5. Bane, C.E., Jr.; Gailani, D. Factor XI as a target for antithrombotic therapy. Drug Discov. Today 2014, 19, 1454-1458. [CrossRef] [PubMed]

6. Al-Horani, R.A.; Desai, U.R. Factor XIa inhibitors: A review of the patent literature. Expert Opin. Ther. Pat. 2016, 26, 323-345. [CrossRef] [PubMed]

7. Schumacher, W.A.; Luettgen, J.M.; Quan, M.L.; Seiffert, D.A. Inhibition of factorXIa as a new approach to anticoagulation. Arterioscler. Thromb. Vasc. Biol. 2010, 30, 388-392. [CrossRef] [PubMed] 
8. Löwenberg, E.C.; Meijers, J.C.; Monia, B.P.; Levi, M. Coagulation factor XI asa novel target for antithrombotic treatment. J. Thromb. Haemost. 2010, 8, 2349-2357. [CrossRef] [PubMed]

9. Gailani, D.; Gruber, A. Factor XI as a Therapeutic Target. Arterioscler. Thromb. Vasc. Biol. 2016, 36, 1316-1322. [CrossRef] [PubMed]

10. Rosenthal, R.; Dreskin, O.; Rosenthal, N. New hemophilia-like disease caused by deficiency of a third plasma thromboplastin factor. Proc. Soc. Exp. Biol. Med. 1953, 82, 171-174. [CrossRef] [PubMed]

11. Meijers, J.C.; Tekelenburg, W.L.; Bouma, B.N.; Bertina, R.M.; Rosendaal, F.R. High levels of coagulation factor XI as a risk factor for venous thrombosis. N. Engl. J. Med. 2000, 342, 696-701. [CrossRef] [PubMed]

12. Salomon, O.; Steinberg, D.M.; Koren-Morag, N.; Tanne, D.; Seligsohn, U. Reduced incidence of ischemic stroke in patients with severe factor XI deficiency. Blood 2008, 111, 4113-4117. [CrossRef] [PubMed]

13. Büller, H.R.; Bethune, C.; Bhanot, S.; Gailani, D.; Monia, B.P.; Raskob, G.E.; Segers, A.; Verhamme, P.; Weitz, J.I. Factor XI antisense oligonucleotide for prevention of venous thrombosis. N. Engl. J. Med. 2015, 372, 232-240. [CrossRef] [PubMed]

14. Perera, V.; Luettgen, J.M.; Wang, Z.; Frost, C.E.; Yones, C.; Russo, C.; Lee, J.; Zhao, Y.; LaCreta, F.P.; Ma, X.; et al. First in human study to assess safety, pharmacokinetics andpharmacodynamics of BMS-962212, a direct, reversible, smallmolecule factor XIa inhibitor in non-Japanese and Japanese healthysubjects. Br. J. Clin. Pharmacol. 2018, 84, 876-887. [CrossRef] [PubMed]

15. Pinto, D.J.P.; Orwat, M.J.; Smith, L.M., 2nd; Quan, M.L.; Lam, P.Y.S.; Rossi, K.A.; Apedo, A.; Bozarth, J.M.; Wu, Y.; Zheng, J.J.; et al. Discovery of a Parenteral Small Molecule Coagulation Factor XIa Inhibitor Clinical Candidate (BMS-962212). J. Med. Chem. 2017, 60, 9703-9723. [CrossRef] [PubMed]

16. Pinto, D.J.; Corte, J.R.; Gilligen, P.J.; Fang, T.; Smith, L.M., II; Wang, Y.; Yang, W.; Ewing, W.R. Novel Macrocycles as Factor XIa Inhibitors. WO2013022818A1 Patent, 14 July 2014.

17. Pinto, D.J.P.; Clark, C.G.; Smith, L.M., II; Orwat, M.J.; Jeon, Y.; Corte, J.R. Tetrahydroisoquinolines Containing Substituted Azoles as Factor Xia Inhibitors. WO2014160668A1 Patent, 2 October 2014.

18. Smith, L.M., 2nd; Orwat, M.J.; Hu, Z.; Han, W.; Wang, C.; Rossi, K.A.; Gilligan, P.J.; Pabbisetty, K.B.; Osuna, H.; Corte, J.R.; et al. Novel phenylalanine derived diamides as Factor XIa inhibitors. Bioorg. Med. Chem. Lett. 2016, 26, 472-478. [CrossRef] [PubMed]

19. Hangeland, J.J.; Friends, T.J.; Rossi, K.A.; Smallheer, J.M.; Wang, C.; Sun, Z.; Corte, J.R.; Fang, T.; Wong, P.C.; Rendina, A.R.; et al. Phenylimidazoles as Potent and Selective Inhibitors of Coagulation Factor XIa with in Vivo Antithrombotic Activity. J. Med. Chem. 2014, 57, 9915-9932. [CrossRef] [PubMed]

20. Rohrig, S.; Hillisch, A.; Strassburger, J.; Schmid, M.V.; Schlemmer, K.-H.; Tersteegen, A.; Buchmuller, A.; Gerdes, C.; Schaffer, M.; Kinzel, T.; et al. Substituted Oxopyridine Derivatives and Use Thereof in the Treatment of Cardiovascular Disorders. WO2014154794A1 Patent, 2 October 2014.

21. Fjellström, O.; Akkaya, S.; Beisel, H.G.; Eriksson, P.O.; Erixon, K.; Gustafsson, D.; Jurva, U.; Kang, D.; Karis, D.; Knecht, W.; et al. Creating novel activated factor XI inhibitors through fragment based lead generation and structure aided drug design. PLoS ONE 2015, 10, e0113705. [CrossRef] [PubMed]

22. Sidique, S.; Ardecky, R.; Su, Y.; Narisawa, S.; Brown, B.; Millán, J.L.; Sergienko, E.; Cosford, N.D. Design and synthesis of pyrazole derivatives aspotent and selective inhibitorsof tissue-nonspecific alkaline phosphatase (TNAP). Bioorg. Med. Chem. Lett. 2009, 19, 222-225. [CrossRef] [PubMed]

23. Fleury, M.; Gendron, R.; Hughes, A.D. Neprilysin Inhibitors. U.S. Patent US20170020904A1 Patent, 26 January 2017.

24. Chae, E.; Shin, Y.J.; Ryu, E.J.; Ji, M.K.; Ryune Cho, N.; Lee, K.H.; Jeong, H.J.; Kim, S.J.; Choi, Y.; Seok, O.K.; et al. Discovery of biological evaluation of pyrazole/imidazole amides as mGlu5 receptor negative allosteric modulators. Bioorg. Med. Chem. Lett. 2013, 23, 2134-2139. [CrossRef] [PubMed]

25. Pinto, D.J.; Smallheer, J.M.; Corte, J.R.; Austin, E.J.; Wang, C.; Fang, T.; Smith, L.M., 2nd; Rossi, K.A.; Rendina, A.R.; Bozarth, J.M.; et al. Structure-based design of inhibitors of coagulation factor XIa withnovel P1 moieties. Bioorg. Med. Chem. Lett. 2015, 25, 1635-1642. [CrossRef] [PubMed]

26. Van Herk, T.; Brussee, J.; van den Nieuwendijk, A.M.; van der Klein, P.A.; IJzerman, A.P.; Stannek, C.; Burmeister, A.; Lorenzen, A. Pyrazole Derivatives as Partial Agonists for the Nicotinic Acid Receptor. J. Med. Chem. 2003, 46, 3945-3951. [CrossRef] [PubMed]

27. Guido, G.; Cedric, G.; Roger, N.; Philippe, P. Pyrazole Derivatives. WO2012168260A1 Patent, 13 December 2012. 
28. Gonzalez, R.J.; Vidal, J.B.; Gual, R.S. New Pyrazole Derivatives as CRAC Channel Modulators. EP2848615A1 Patent, 18 March 2015.

29. Nobuhisa, F.; Yohei, I.; Tetsuya, K.; Kuniko, S. Phenylalanine Derivative. JP2014227401A Patent, 8 December 2014.

Sample Availability: Samples of the compounds 7a $\sim 7 \mathrm{zc}$ are available from the authors.

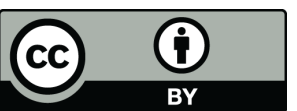

(C) 2018 by the authors. Licensee MDPI, Basel, Switzerland. This article is an open access article distributed under the terms and conditions of the Creative Commons Attribution (CC BY) license (http:/ / creativecommons.org/licenses/by/4.0/). 